\title{
My Research Collaborations with Chinese Scientists over the Past Three Decades
}

\author{
Robert Cooper Liebermann \\ Mineral Physics Institute and Department of Geosciences, Stony Brook University, Stony Brook, NY, USA \\ Email: Robert.Liebermann@stonybrook.edu
}

How to cite this paper: Liebermann, R.C. (2021) My Research Collaborations with Chinese Scientists over the Past Three Decades. International Journal of Geosciences, 12, 960-983.

https://doi.org/10.4236/ijg.2021.1210050

Received: September 7, 2021

Accepted: October 24, 2021

Published: October 27, 2021

Copyright (C) 2021 by author(s) and Scientific Research Publishing Inc. This work is licensed under the Creative Commons Attribution International License (CC BY 4.0).

http://creativecommons.org/licenses/by/4.0/

\begin{abstract}
For more than three decades, I have been fortunate in working with Chinese graduate students and postdoctoral research scientists in our High-Pressure Laboratory at Stony Brook University. These colleagues have conducted a wide variety of experiments at high pressures and temperatures in collaboration with our other students and researchers. These studies utilized transmission electron microscopy, ultrasonic interferometry, X-ray powder diffraction and synchrotron X-radiation to investigate phase transitions, thermal equations of state, sound velocities, atomic diffusion, dislocation dissociation and deviatoric stress in high-pressure apparatus. During this period, I have also visited high-pressure laboratories in the mainland of China and Taiwan on several occasions. The objective of this paper is to relate this history.
\end{abstract}

\section{Keywords}

Mineral Physics, High Pressure, High Temperature, Anisotropy and Lateral Heterogeneity of the Earth's Mantle

\section{Introduction}

Over the past decade, I have concentrated on writing papers on my history pursuing a scientific career in mineral physics. Recently, I have published papers on "Stony Brook's high-pressure laboratory collaborations with French scientists" and "Stony Brook's collaborations with Czech scientists" in the International Journal of Geosciences [1] [2]. This new paper is of a similar genre.

In the 1960s and during the Cultural Revolution in China, only students from Taiwan could come to the U.S. to study. In the field of mineral physics, perhaps the most prominent of these students were Ho-kwang [Dave] Mao and Lin-gun [John] Liu who did their doctoral research in the laboratory of William Bassett and Taro Takahashi at the University of Rochester using diamond-anvil cell 
techniques to study the behavior of minerals at high pressures (Figure 1).

Following the end of the Cultural Revolution in China in the 1970s, universities started admitting students in 1977, and in the early 1980s Chinese students from China began to apply for graduate study in foreign countries. Two of these, Yanbin Wang and Yusheng Zhao came to Stony Brook in the early 1980s, initially to work in the laboratory of Teng-fong Wong and later to study with other faculty [Yusheng with Don Weidner and Yanbin with me]. It was my other graduate students Gabriel Gwanmesia and Anne Remsberg who induced Yanbin to join our research group.

After completing his doctoral studies in the laboratory of Charlie Prewitt at Stony Brook, Xing Liu joined my research group and pursued a variety of topics, many of which used $\mathrm{CaGeO}_{3}$ as a crystallographic analog of silicates [3] [4]. For his M.S. thesis, Ren Lu studied the kinetic rates of transformation between the garnet and perovskite phases of $\mathrm{CaGeO}_{3}$, (see the 1988 photo of our team in front of USSA-2000 high-pressure press in Figure 2).

Over the subsequent 35 years, I have profited from interacting with a series of outstanding Chinese graduate students and postdoctoral research visitors in our High-Pressure Laboratory, including graduate students: Baosheng Li, Yue Meng [advisor Don Weidner], Jun Liu, and students of Baosheng Li: Xuebing Wang, Ting Chen, Xintong Qi, Siheng Wang and Sibo Chen [see Figures 3-6 and list of thesis titles appended below] and postdoctoral research scientists: Ganglin Chen, Jiuhua Chen, Jianzhong Zhang, Jennifer Kung and Yongtao Zou [Figures 7-10].

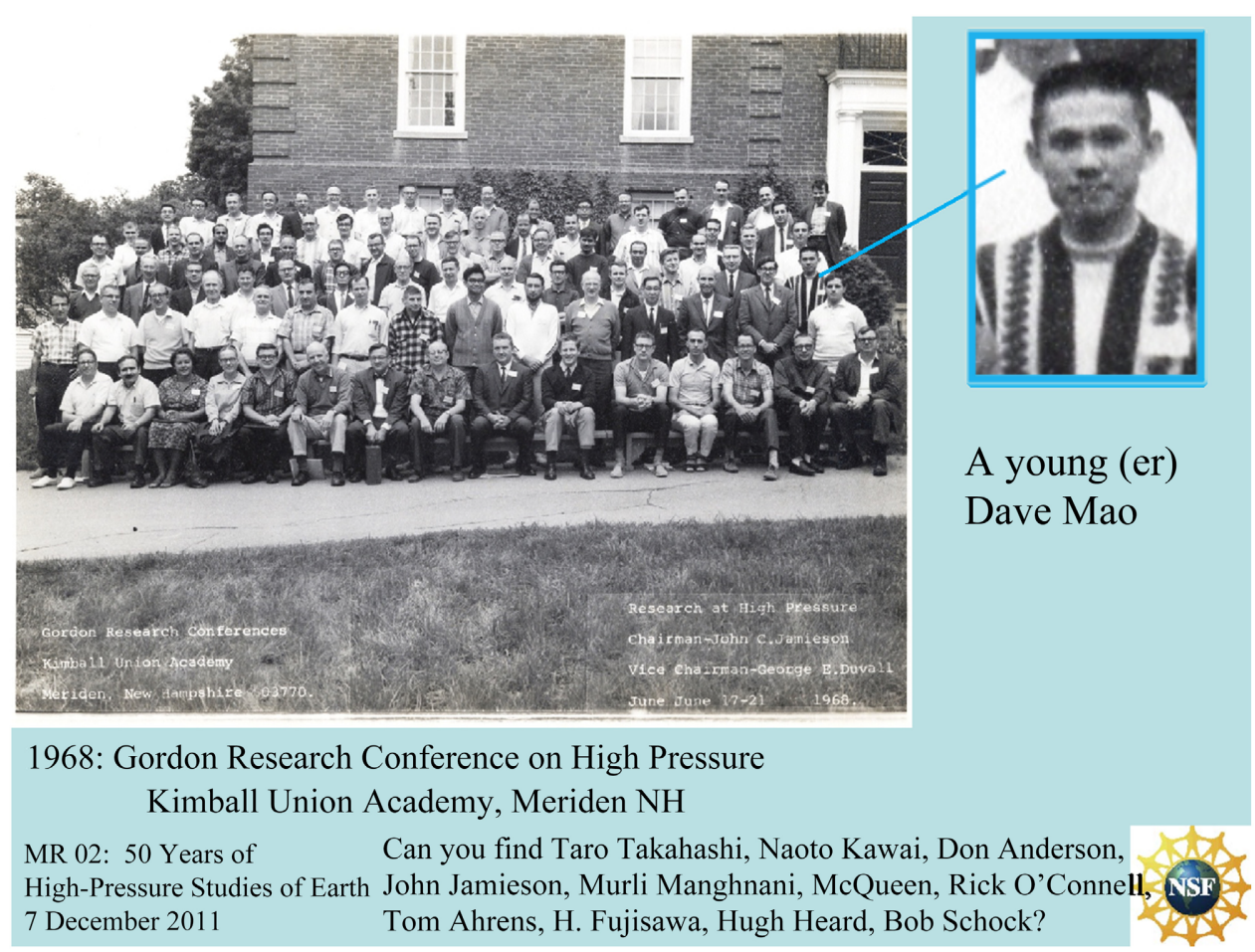

Figure 1. Dave Mao at 1968 Gordon Research Conference on high pressure. 


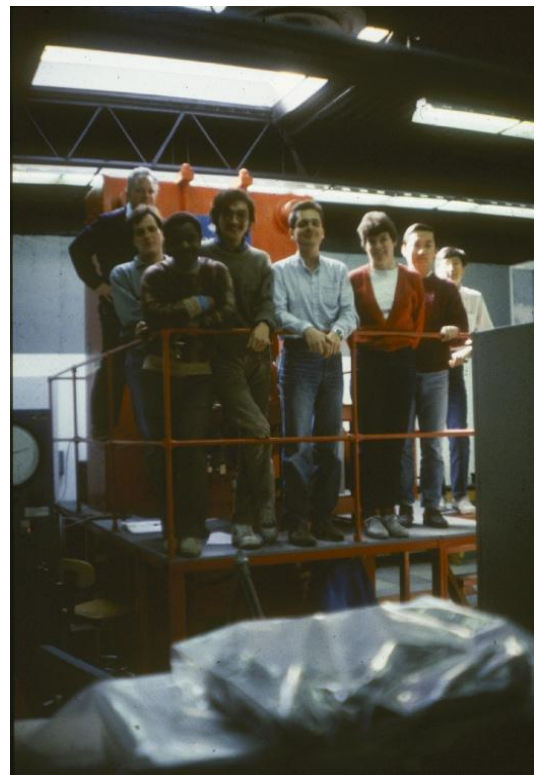

Figure 2. Bob's research team from China, France, Cameroon and USA circa 1988. L. to R. Bob (USA), Yves Bertran (France), Gabriel Gwanmesia (Cameroon), Ren Lu (China), François Guyot (France), Anne Remsberg (USA), Yanbin Wang (China). Xing Liu (China) standing in front of the 2000-ton Uniaxial Split-Sphere Apparatus [USSA-2000].

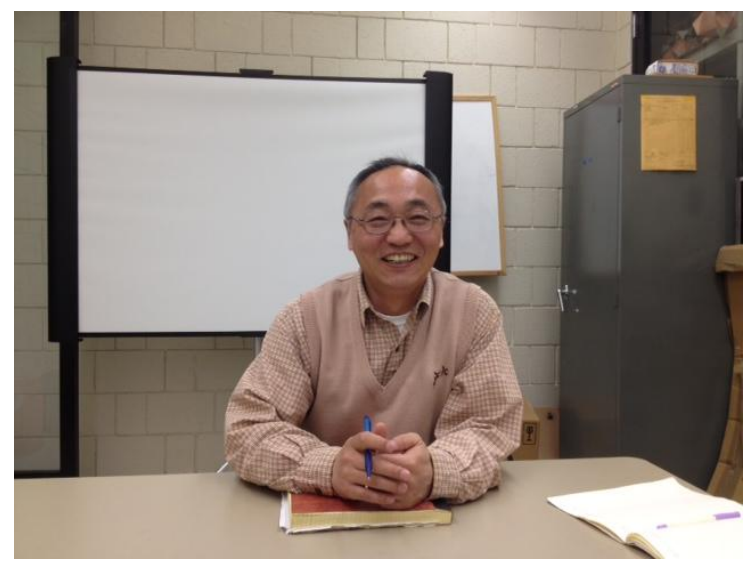

Figure 3. Baosheng Li [MS 1993, PhD 1996].

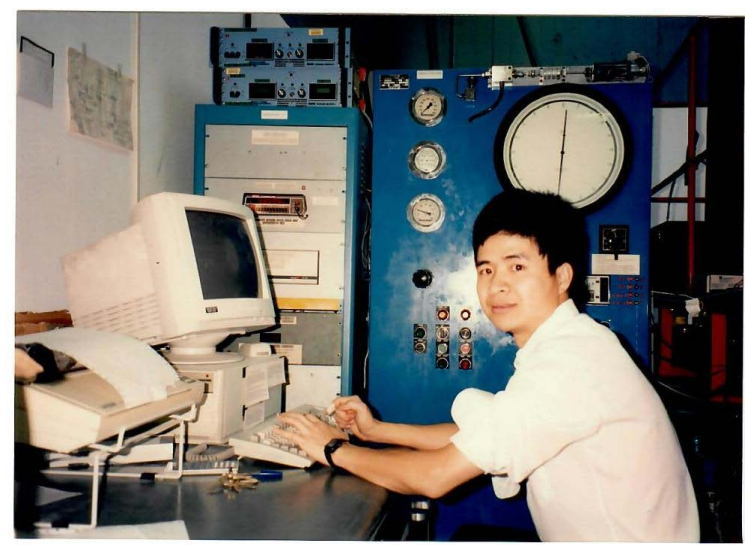

Figure 4. Jun Liu in the high-pressure lab circa 1996 [MS 1997, PhD 2001]. 


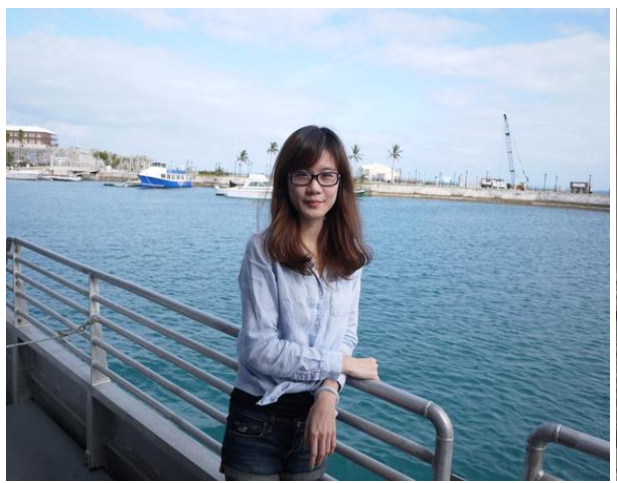

(a)

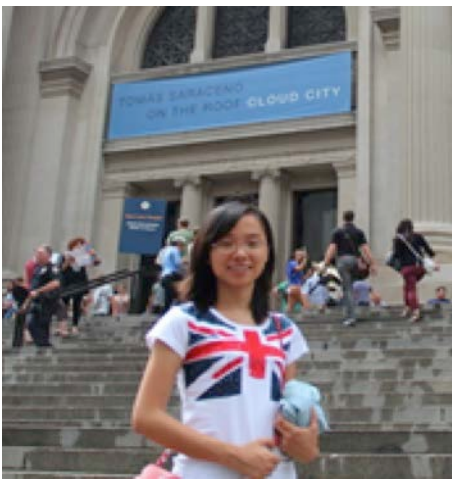

(b)

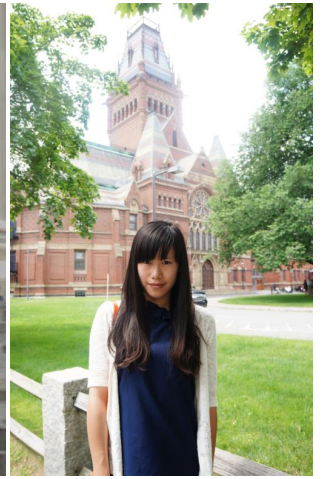

(c)

Figure 5. L. to R. graduate students of Baosheng Li from China in 2010-2019. Xuebing Wang (a), Ting Chen (b) and Xintong Qi (c).

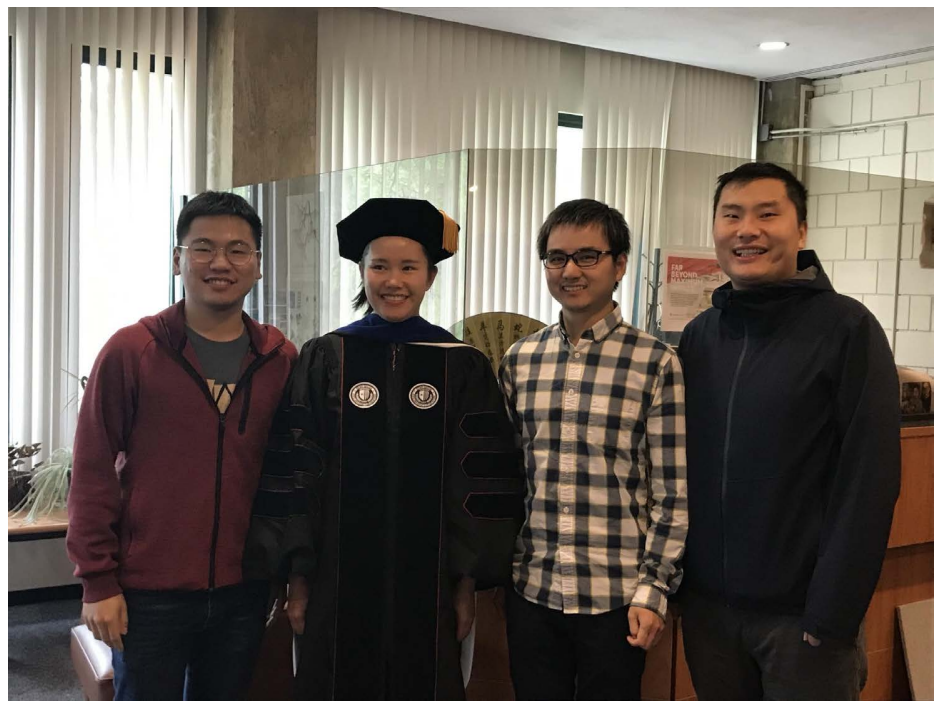

Figure 6. Graduate students of Baosheng Li with new PhD Xintong Qi and postdoc Nao Cai in 2019. L. to R. Siheng Wang, Xintong Qi, Nao Cai and Sibo Chen.

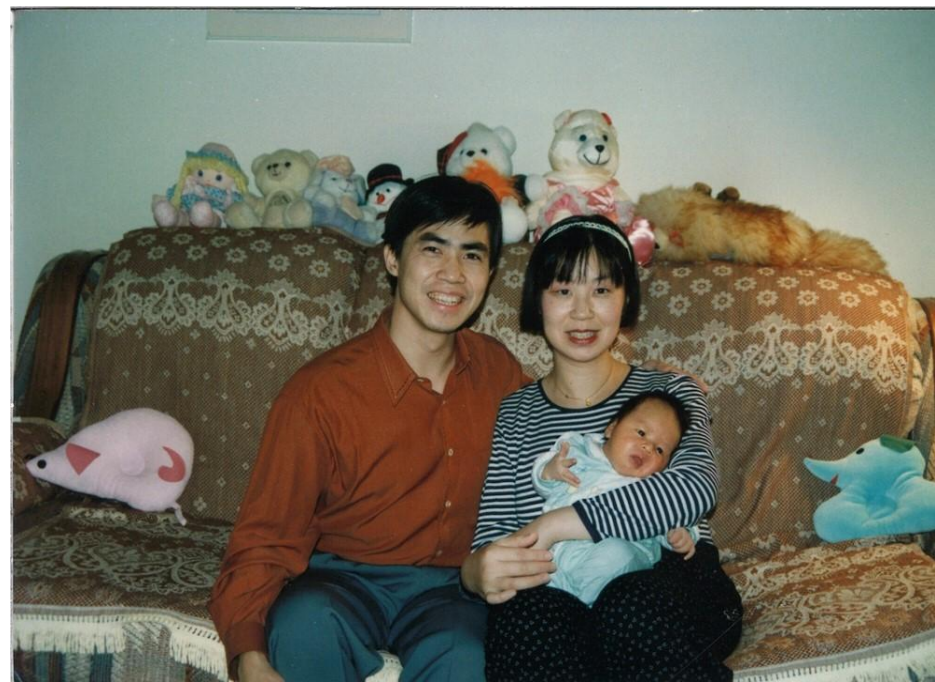

Figure 7. Ganglin Chen and family. 


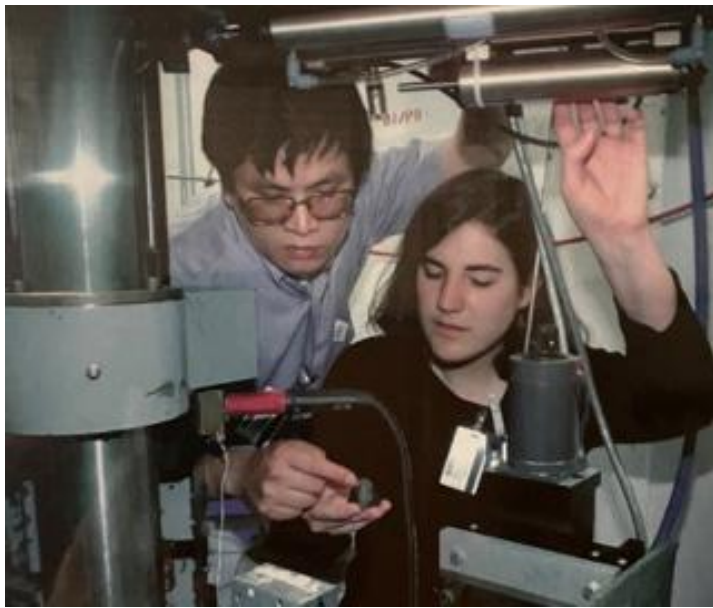

Figure 8. Jianzhong Zhang [“Z”] with CHiPR Summer Scholar in High-Pressure Laboratory.

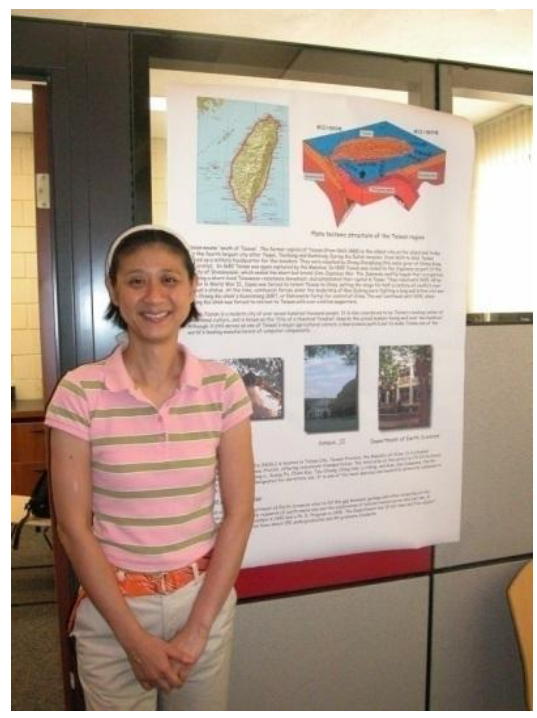

Figure 9. Jennifer Kung and poster AGU meeting.

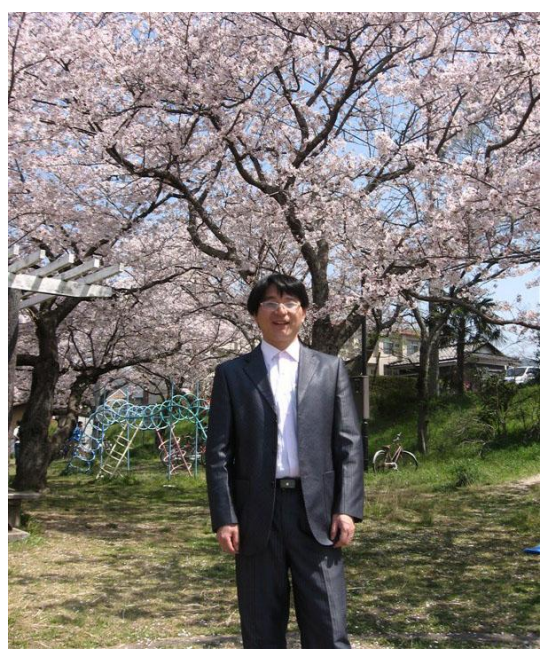

Figure 10. Yongtao Zou and blossoming sakura tree in Matsuyama, Japan. 


\section{Scientific Studies and Research Advances}

These studies utilized transmission electron microscopy, ultrasonic interferometry, X-ray powder diffraction and synchrotron X-radiation to investigate mineralogical phase transitions, thermal equations of state, sound velocities, atomic diffusion, dislocation dissociation and deviatoric stress in high-pressure apparatus. Experiments at high pressure were conducted in large-volume, multi-anvil presses, including the 2000-ton Uniaxial Split-Sphere Apparatus [USSA-2000] seen in Figure 11 and Figure 12 and the 1000-ton Uniaxial Split-Cylinder Apparatus [USCA-1000] seen in Figure 15 and Figure 16.

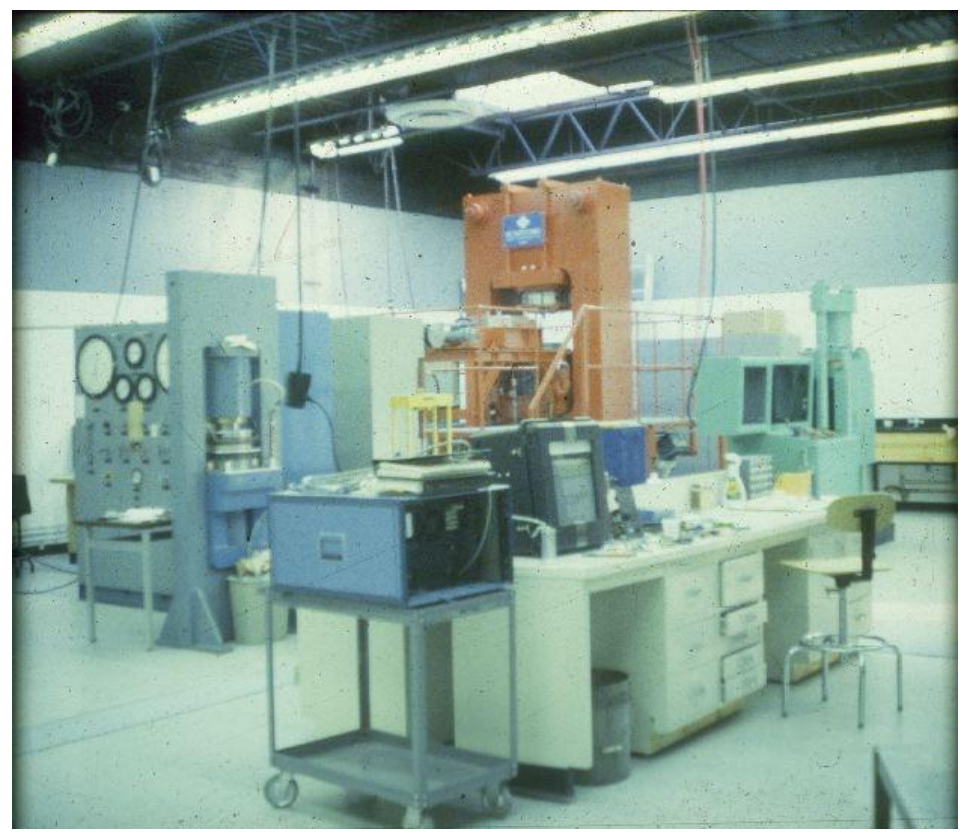

Figure 11. High pressure laboratory [1984 to 2021].

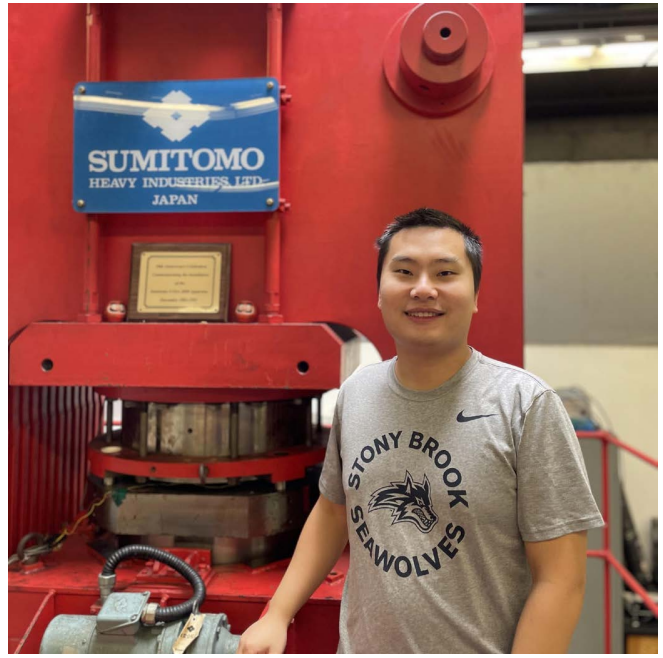

(a)

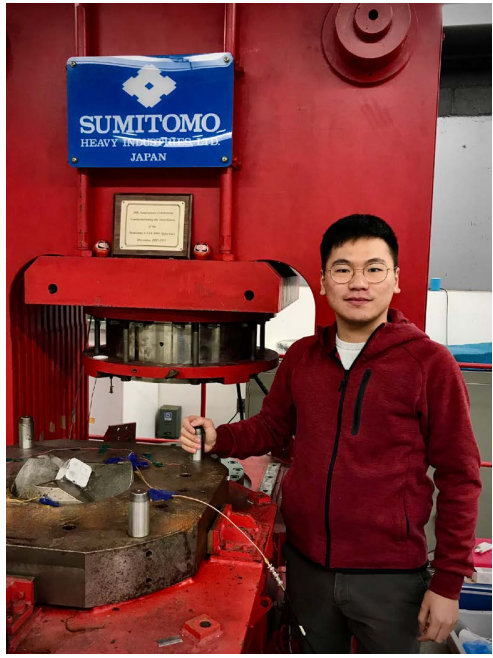

(b)

Figure 12. (a) Sibo Chen (L) and (b) Siheng Wang (R) with USSA-2000: Uniaxial Split-Sphere Apparatus in Stony Brook High Pressure Laboratory circa 2020. 
Crystal dislocations and their use in mineral physics studies

Using techniques developed by Ingrin and Liebermann [5], Yanbin Wang and James Boland from Australia determined the dislocation density in olivine single crystals observed with optical microscopy to characterize the degree of deviatoric stress in high P-T experiments; see Figure 13 [6]. See also review by Liebermann and Yanbin Wang [7].

Transmission electron microscopy [ TEM]

Later, Yanbin utilized transmission electron microscopy to study dislocation dissociation and twinning in minerals in collaboration with colleagues from France, including Jean-Paul Poirier, François Guyot and Isabelle Martinez [8] [9] [10] [11] [12] and Patrick Cordier and Paul Raterron [13] and the research group of Michael Dudley in the Department of Materials Science and Engineering at Stony Brook [14] [15]. Yanbin and others also exploited the advantages of TEM to study phase transitions, domain and modulated microstructures and iron partitioning [8] [11] [12] [16] [17] [18].

Powder X-ray diffraction and thermal equations-of-state

Laboratory X-ray facilities, and later synchrotron X-radiation facilities enabled investigations of thermal equations of state and phase transitions in minerals by Xing Liu, Yanbin Wang, Yue Meng, and Jun Liu [3] [19]-[28].

Atomic diffusion in minerals at high pressure and temperature

In collaboration with the laboratory of Olivier Jaoul in Orsay, France, Jianxhong Zhang and Yanbin Wang conducted experiments at high $\mathrm{P}$ and $\mathrm{T}$ to measure atomic diffusion San Carlos olivine, see Bejina, Raterron, Zhang [29] [Figure 14].

Other research interests

Our laboratory has always had a special interest in the perovskite phase of ( $\mathrm{Mg}, \mathrm{Fe}) \mathrm{SiO}_{3}$. See especially the studies of Yanbin Wang [9] [10] [11] [12] [16] [18] and later Ganglin Chen [30].

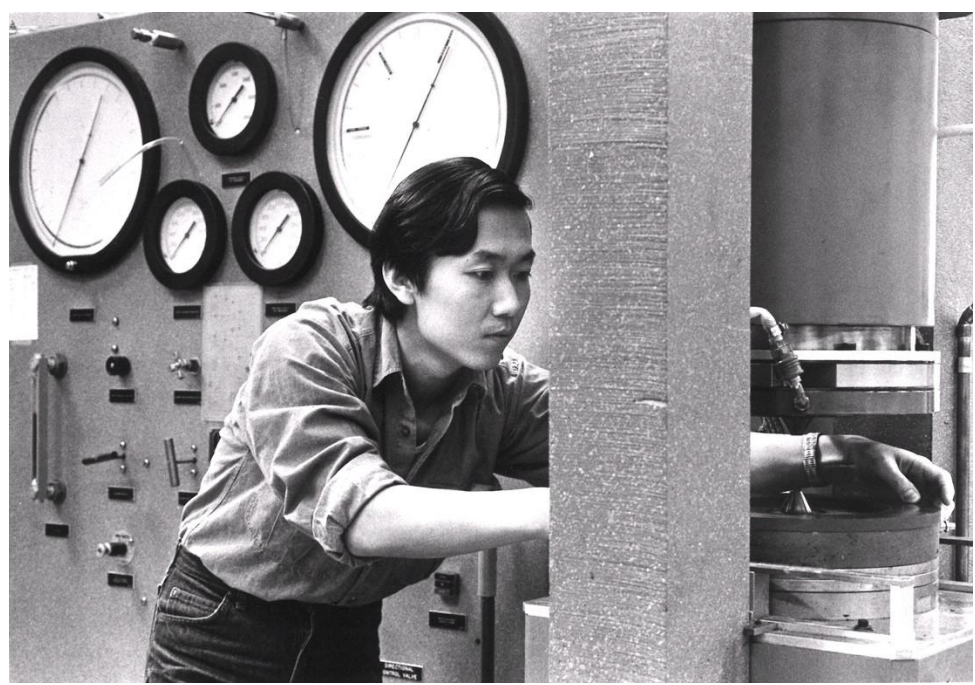

Figure 13. Yanbin Wang conducting tests in the girdle-anvil, solid-media apparatus to determine the degree of deviatoric stress imposed on the samples during high P-T experiments [6]. 


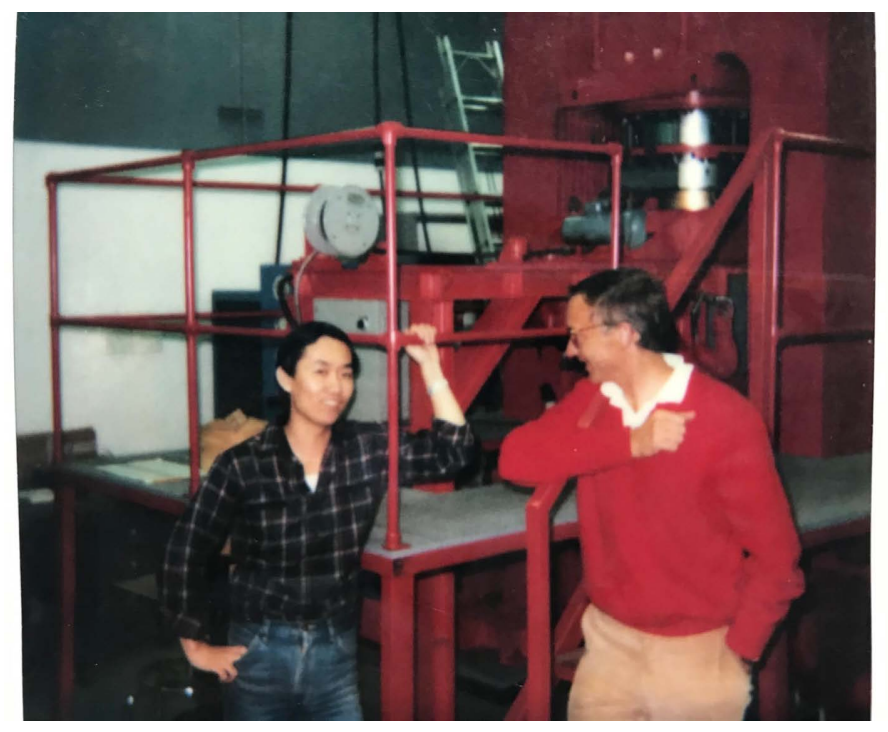

Figure 14. Photo of graduate student Yanbin Wang (L) and Olivier Jaoul (R) planning how to study atomic diffusion at high pressures using the USSA-2000 apparatus.

Other investigations have focused on the coesite and stishovite phases of $\mathrm{SiO}_{2}$. These studies were led by Jianzhong Zhang [31] [32], Jun Liu [23] [33] and Baosheng Li [34] and most recently Ting Chen [35] [36].

Ultrasonic interferometry. Technical development and early studies

A principal focus of the research activities of our research group in the past two decades has been to utilize ultrasonic interferometry to measure sound velocities of materials at high pressures and temperatures, initially in our High-Pressure Laboratory at Stony Brook and later at the synchrotron X-radiation facilities of the U. S. Department of Energy at the National Synchrotron Light Source [NSLS] of Brookhaven National Laboratory and at the Advanced Photon Source [APS] of Argonne National Laboratory.

This research initiative grew out a collaboration between Baosheng Li at Stony Brook and Ian Jackson at the Australian National University [ANU]. It combined the system of ultrasonic interferometry developed by Jackson with the 1000-ton Uniaxial Split Cylinder Apparatus [USCA-1000] equipped with a Walker-type module [aka the Kennedy-Getting apparatus] in our High-Pressure Laboratory, (see Figure 15 and Figure 16).

For details of the use of ultrasonic interferometry in conjunction with multi-anvil, high-pressure apparatus, see review papers by Baosheng Li and colleagues [37]-[43]. In a particularly important study, Xuebing Wang led an all-Chinese research team to develop an alumina travel time gauge which provides in situ determination of pressure in multi-anvil apparatus for experiments performed without synchrotron X-radiation [44].

This development of ultrasonic interferometry in multi-anvil, high-pressure apparatus was subsequently exploited by postdocs [Ganglin Chen, Jennifer Kung, Yongtao Zou, Jianzhong Zhang] and grad students of Baosheng Li [Xuebing Wang, Ting Chen, Xintong Qi, Siheng Wang, Sibo Chen], (see Figure 17 \& Figure 18). 


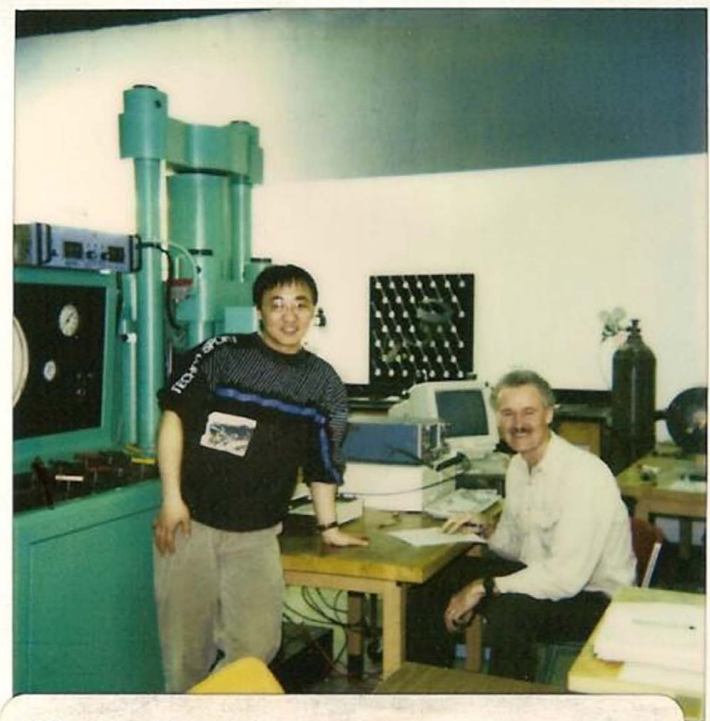

13 May 1994

Baosheng Li and Ian Jackson with in situ ultrasonic experiment at high P

Figure 15. Baosheng Li and Ian Jackson using the 1000-ton Uniaxial Split-Cylinder Apparatus [USCA-1000], aka the Kennedy-Getting press, to develop their new experiments extending ultrasonic interferometric measurements of sound velocities to $10 \mathrm{GPa}$ in 1994 .

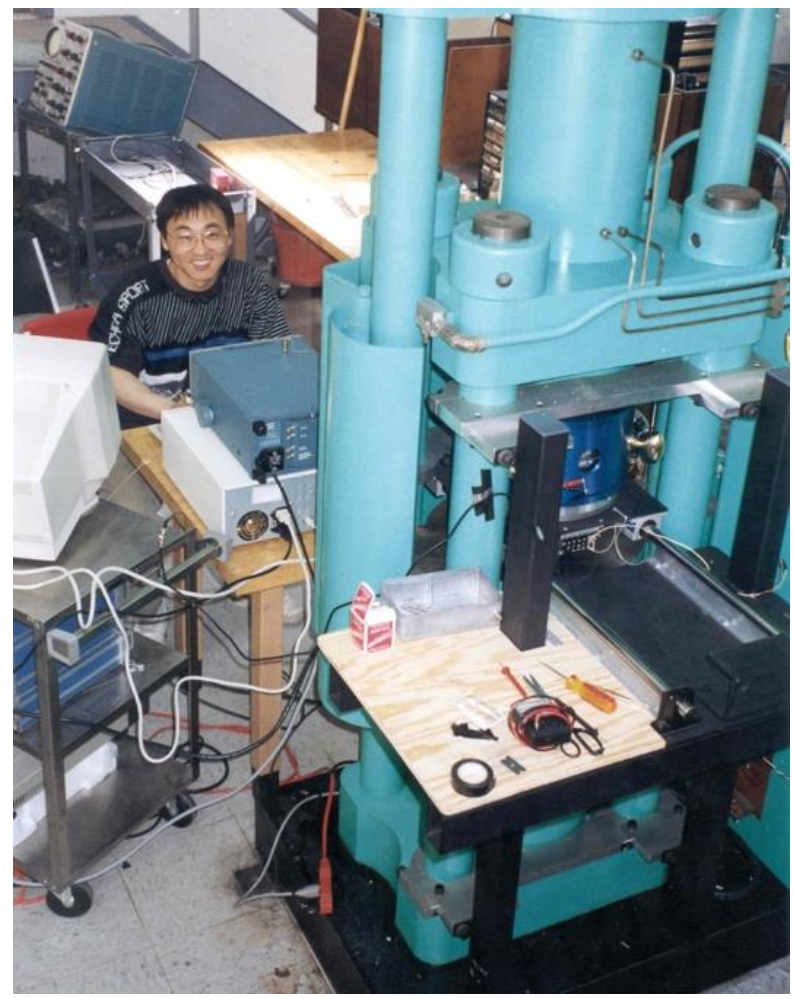

Figure 16. Baosheng Li and Kennedy-Getting press with Walker-type module in High-Pressure Lab in 1994. 


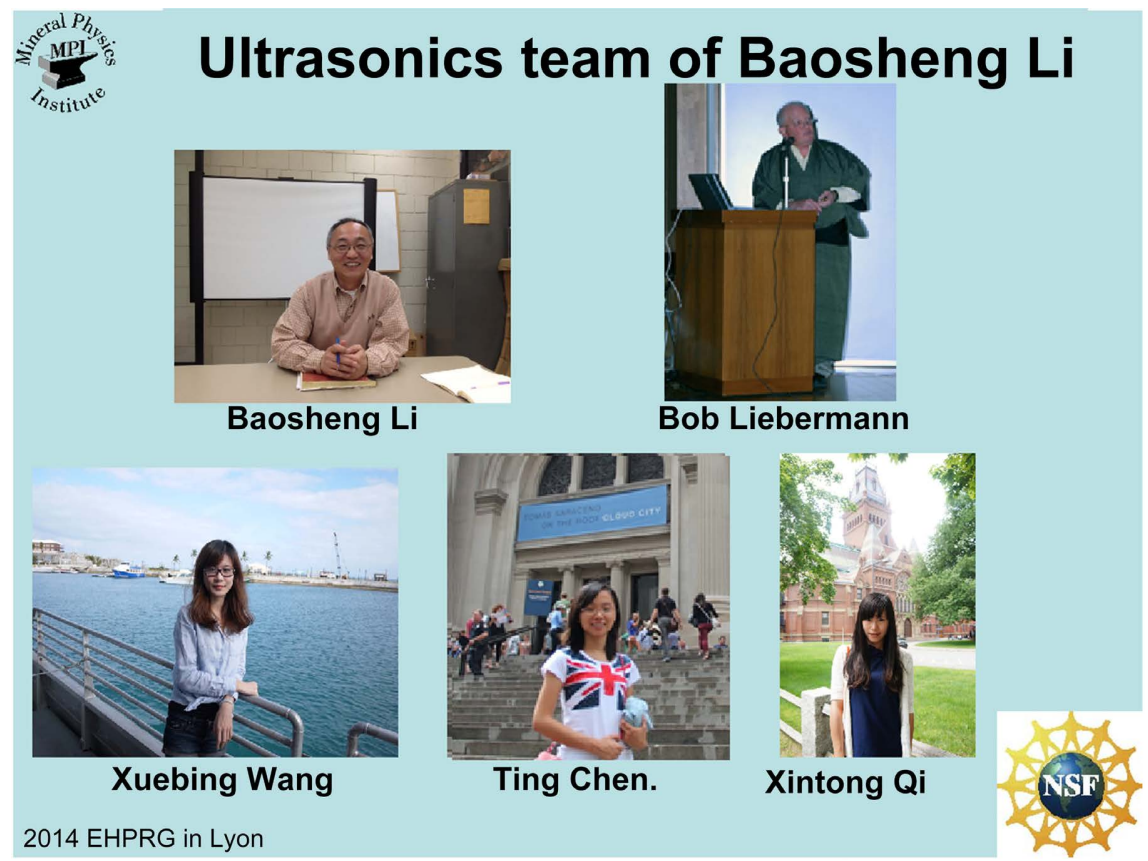

Figure 17. Ultrasonics team of Baosheng Li 2010-2019.

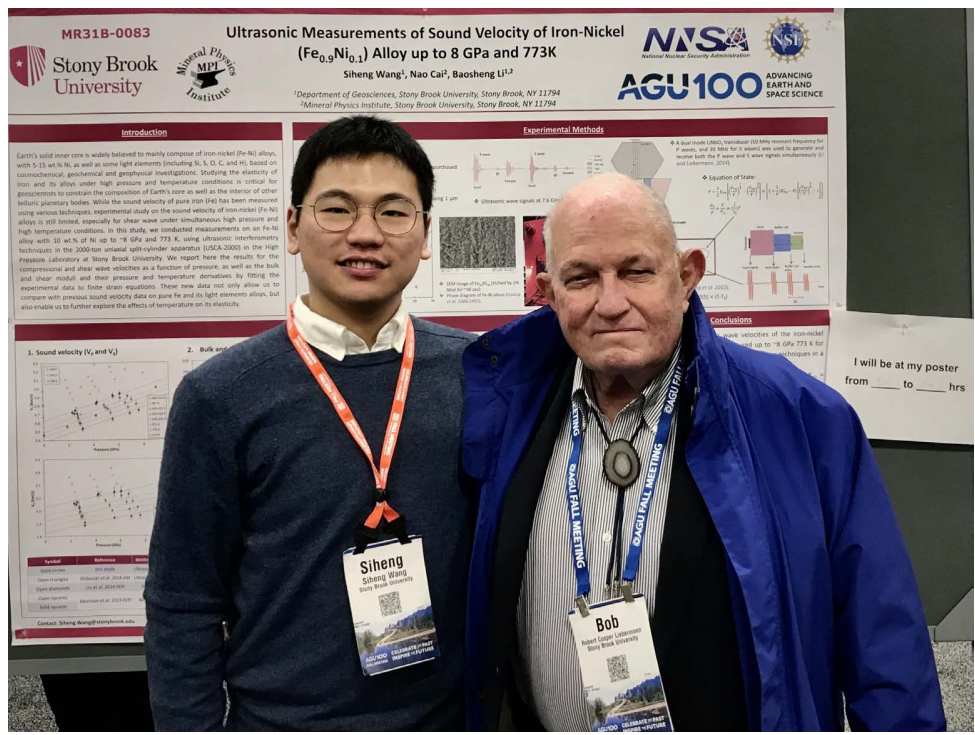

Figure 18. Siheng Wang and Bob with poster at Fall AGU meeting in 2019.

Most of these studies were done using polycrystalline specimens following techniques developed by Liebermann in Ted Ringwood's lab at the ANU [45] and later extended to higher pressures by Gwanmesia [46] [47] at Stony Brook [primarily in the USSA-2000 press, see photos of Sibo Chen and Siheng Wang above in Figure 12(a) and Figure 12(b)].

However, several significant projects involved measurements on single-crystal specimens of olivine and MgO by Ganglin Chen [48] [49] and ZnO by Baosheng Li and Jianzhong Zhang [50] [51].

Among the minerals or their crystallographic analogs which have been studied 
by our Chinese colleagues with our ultrasonic interferometry at high pressure and temperatures are:

$\mathrm{CaTiO}_{3}-\mathrm{CaSiO}_{3}$ by Ganglin Chen [52].

$\mathrm{Mg}_{2} \mathrm{SiO}_{4}$ wadsleyite and ringwoodite by Baosheng Li [53] [54] [55].

Majorite garnets by Ganglin Chen [56] [57], Jun Liu and Ganglin Chen [58] [59], Jianzhong Zhang, Jennifer Kung and Baosheng Li [60], Liping Wang [61].

ZnO by Jianzhong Zhang [62].

(Mg, Fe)O by Jennifer Kung, Baosheng Li and Jianzhong Zhang [63].

Dopside by Baosheng Li [64].

$\mathrm{MgSiO}_{3}$ orthpyroxene and clinopyroxene by Jennifer Kung and Baosheng Li [65] [66] and Siheng Wang, Ting Chen, Xintong Qi, Nao Cai and Baosheng Li [67].

Kilbourne Hole peridotite by Xuebing Wang, Ting Chen, Yongtao Zou and Baosheng Li [68].

Magnetite by Yongtao Zou, Ting Chen, Xintong Qi and Baosheng Li [69].

Liebermannite by Ting Chen [70].

Tungsten by Xintong Qi, Nao Cai, Siheng Wang, and Baosheng Li [71].

Phase A by Nao Cai, Xintong Qi, Ting Chen, Siheng Wang and Baosheng Li [72].

Iron-Nickel $\left[\mathrm{Fe}_{90} \mathrm{Ni}_{10}\right]$ by Siheng Wang, Nao Cai, Xintong Qi, Sibo Chen, and Baosheng Li [73].

Topaz by Sibo Chen, Nao Cai, Siheng Wang, Xintong Qi and Baosheng Li [74].

Niobium by Yongtao Zou, Xintong Qi, Xuebing Wang, Ting Chen, and Baosheng Li [75].

Tantalum by Xintong Qi, Siheng Wang, Sibo Chen, Nao Cai and Baosheng Li [76].

23A Phase by Nao Cai, Ting Chen, Xintong Qi, Toru Inoue, and Baosheng Li [77].

Praseodymium by Nao Cai, Ting Chen, Xintong Qi and Baosheng Li [78].

\section{Visits of Author to the Mainland of China and Taiwan}

In addition to hosting Chinese graduate students and postdocs in our High-Pressure Laboratory, Bob has visited their universities on four occasions. 1997: Jilin University in Changchun

At the US-Japan High-Pressure Seminar at Turtle Bay, Hawaii in 1986, I met Guangtian Zou from Jilin University in Changchun; in 1997 with support from the World Bank, he invited me to spend two weeks in his State Key Laboratory giving lectures and discussing research projects with his students and colleagues (Figure 19). They also led me on a field trip to the border of North Korea and the site of an exhibit for the Last Emperor of China, as seen in Figure 20. Another of my connections to Jilin University is Jiuhua Chen, who was an undergraduate there in the 1980s, obtained his $\mathrm{PhD}$ in Tsukuba, Japan and then spent 13 years as a research colleague in the Mineral Physics Institute at Stony Brook. 


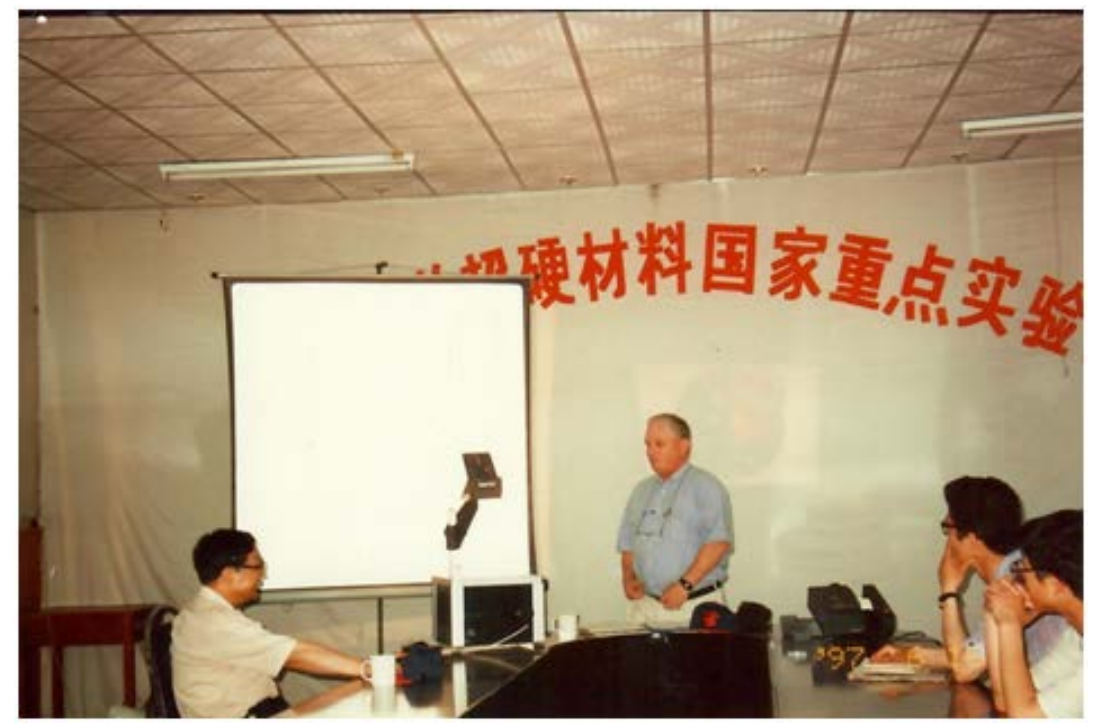

Figure 19. Bob giving seminar at Jilin University in 1997 with host Guangtian Zou seated at left.

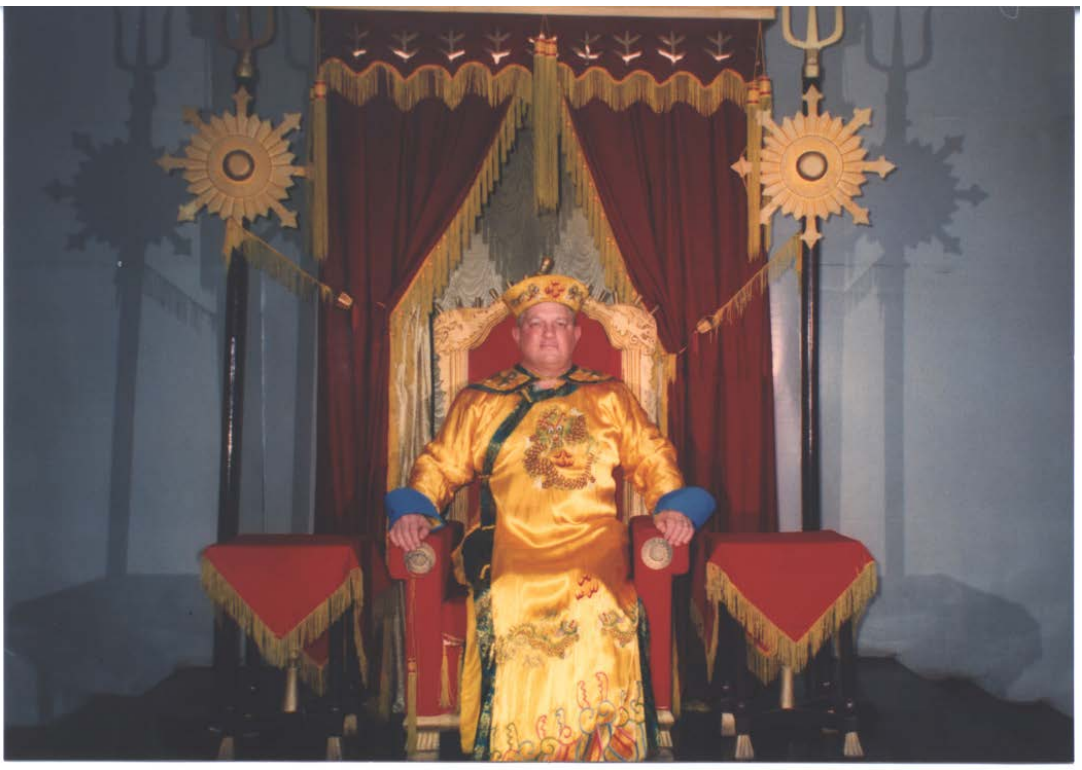

Figure 20. 1997: Bob on throne of the Puyi, the Last Emperor of China.

Following my time in Changchun, I visited Beijing where I was hosted by the sister of Bianjia Li [wife of Baosheng]; she led me on visits to various tourist attractions on alternate days and allowed me to find other sites on my own the other days, including Tiananmen Square, the Forbidden City, the old and new Summer Palaces. A day trip outside of Beijing allowed me to see the Great Wall of China at Mutianyu.

\section{7: National Cheng Kung University in Tainan}

In 2007, I was invited by Jennifer Kung, former postdoc at Stony Brook, to visit her laboratory at the National Cheng Kung University in Tainan (Figure 21); during that visit, I delivered lectures in her department of Earth Sciences 
and met the father of Tony $\mathrm{Yu}$ who was Dean of the College of Science [Tony was then a postdoc at Stony Brook], and also visited tourist sites in Taipei and along the south coast of Taiwan.

2009: Harbin Institute of Technology [HIT] in Harbin

In 2009, I was invited by Haozhe Liu [former postdoc in research group of Jiuhua Chen and Don Weidner at Stony Brook] to visit the Harbin Institute of Technology in Harbin, accompanied by my wife Barbara. During this visit, he proudly exhibited his new cubic anvil press and I presented an invited lecture at IUCr High Pressure workshop (Figures 22-24).

We then traveled to Beijing to explore tourist sites that I had remembered from 1997. We were hosted by Changqin Jin and housed in the guest house at the Institute of Physics of the Chinese Academy of Sciences [see photo in Jin's laboratory in Figure 25]; Jin and I had first met at Stony Brook when he was visiting Jiuhua Chen.

During our time in Beijing, we took side trips to the Ming Tombs enroute to the Great Wall of China at Badaling [Figure 26] and to Xian to see the famous Terra Cotta Warriors. After Beijing, we took a boat trip on the Li River enroute to Guilin [Figure 27].

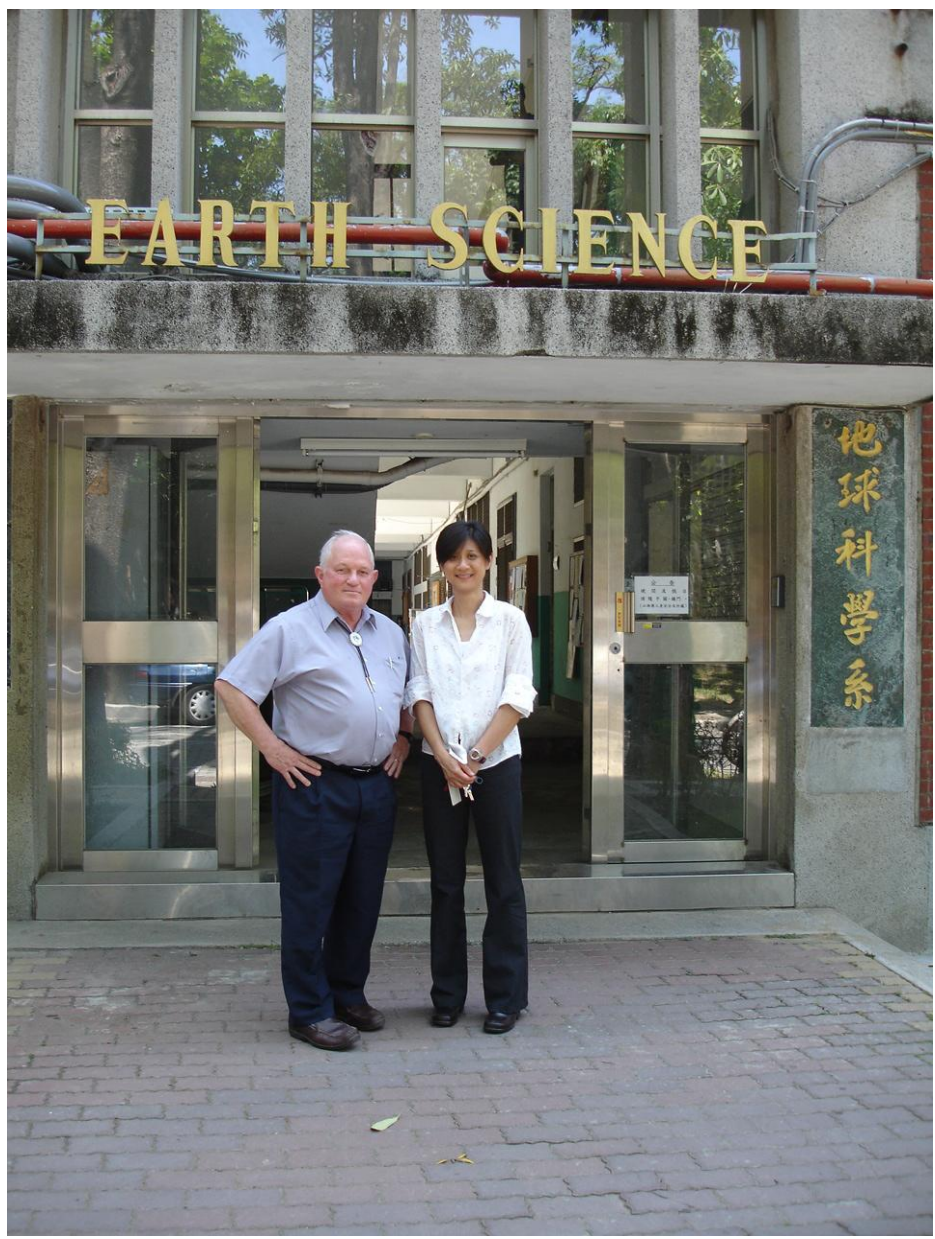

Figure 21. Bob with Jennifer Kung at National Cheng Kung University in Tainan 2007. 


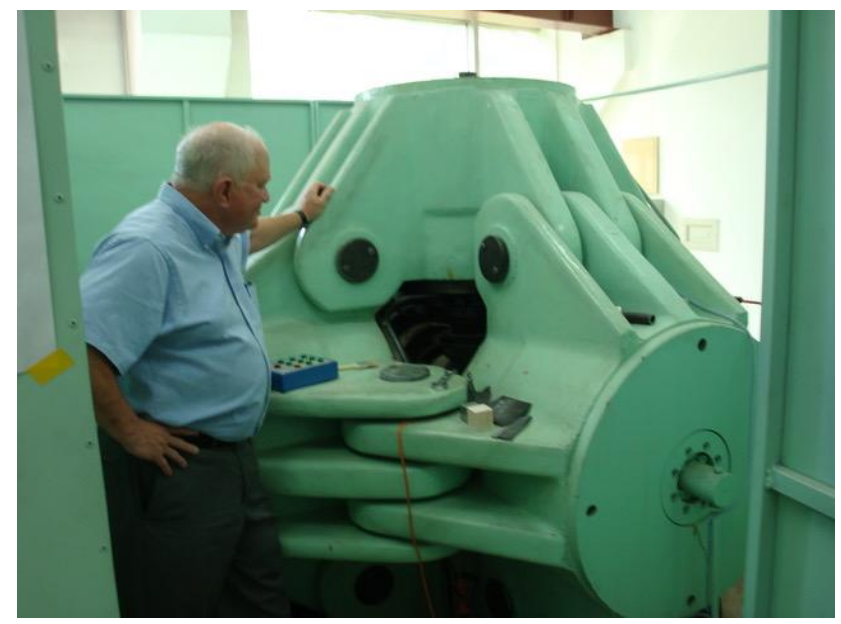

Figure 22. Bob with cubic anvil press in laboratory of Haozhe Liu at Harbin Institute of Technology in 2009.

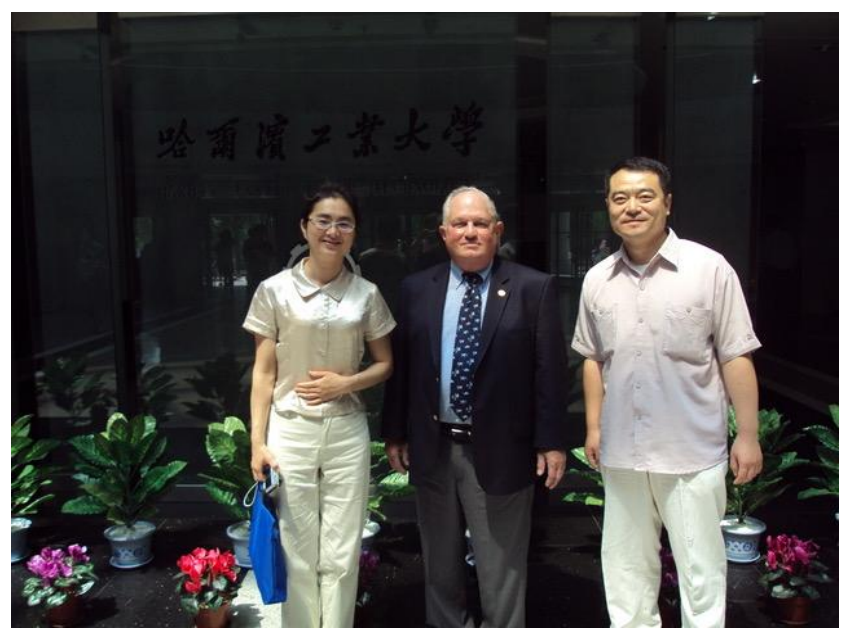

Figure 23. Bob with Haozhe Liu and his scientist wife Luhong Wang during my visit to Harbin in 2009.

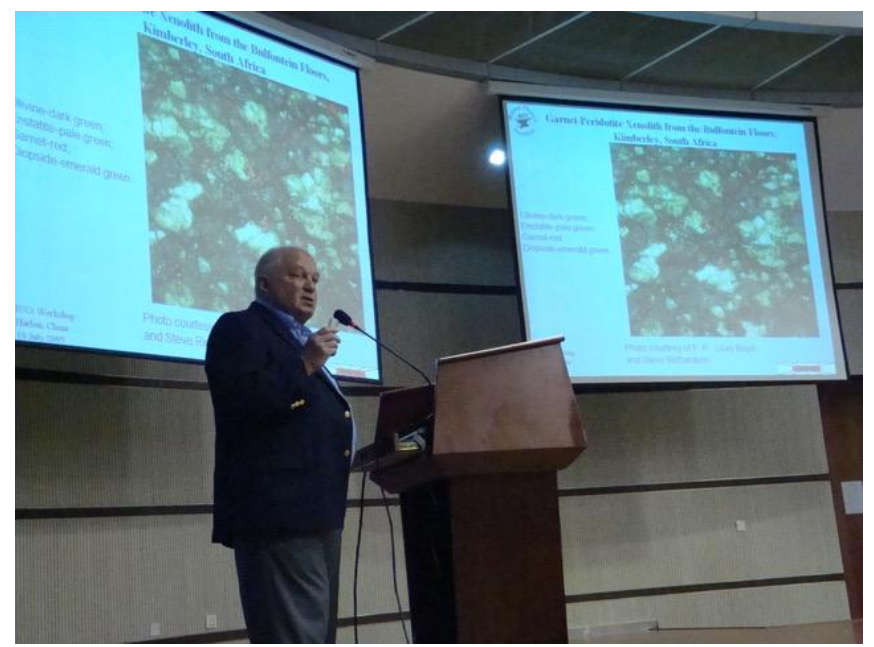

Figure 24. Bob delivering invited lecture at IUCr High Pressure workshop at Harbin Institute of Technology in 2009. 


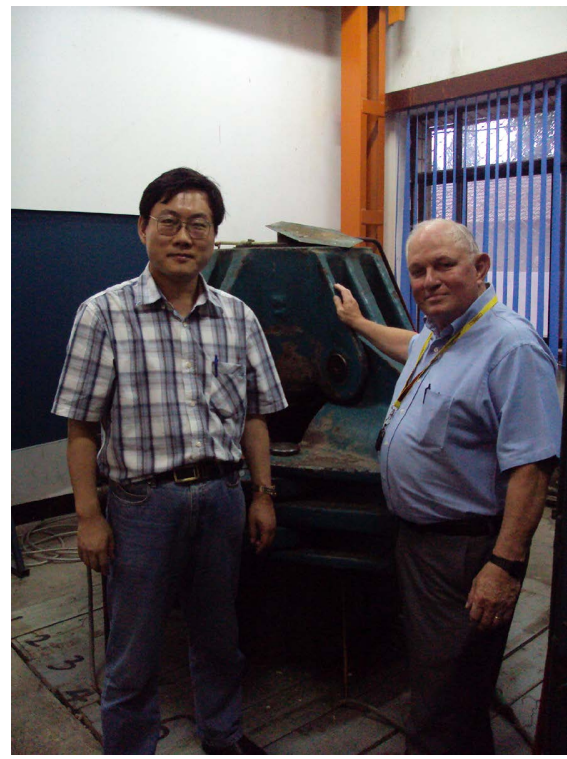

Figure 25. Cubic anvil apparatus at Institute of Physics of the Chinese Academy of Sciences with Changqing Jin and Bob in 2009.

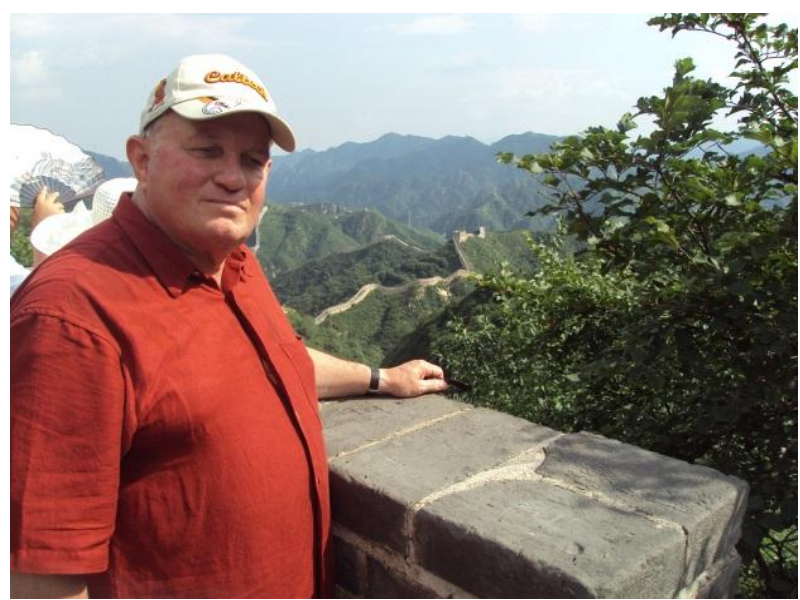

Figure 26. Bob on the Great Wall at Badaling accompanied by Barbara.

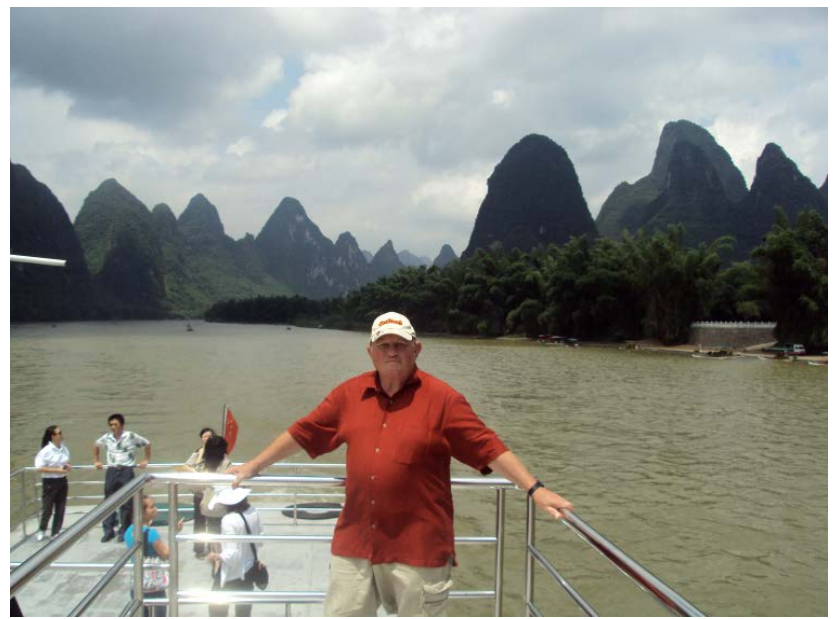

Figure 27. Bob on boat trip on the Li River enroute to Guilin with Barbara. 


\section{1: China University of Geosciences in Wuhan}

At the Fall 2008 AGU meeting, I co-chaired a session honoring Harry Green with Zhenmin Jin from the China University of Geosciences in Wuhan. In 2011, I was invited by Professor Jin to visit the CIG in Wuhan, accompanied by my colleague Yanbin Wang. I delivered a few seminars [Figure 28] and visited their experimental laboratories [see Figure 29], in addition to exploring tourist attractions in the city of Wuhan. We also visited field sites for ultra-high pressure metamorphic rocks near Dabie-shan [Figure 30].

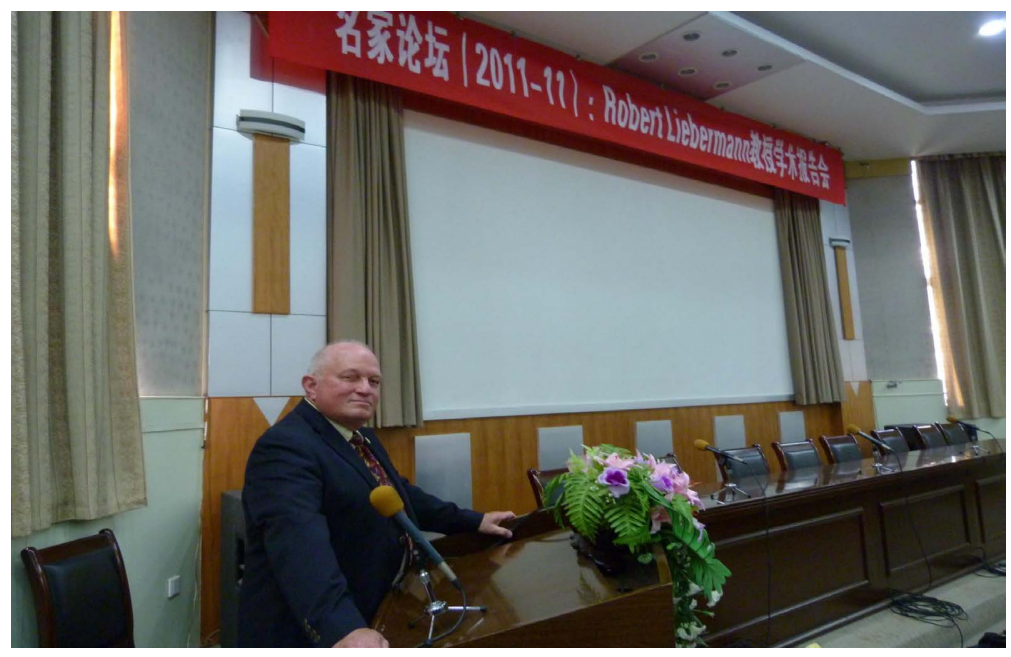

Figure 28. Bob delivering lecture at China University of Geosciences [CUG] in Wuhan in 2011.

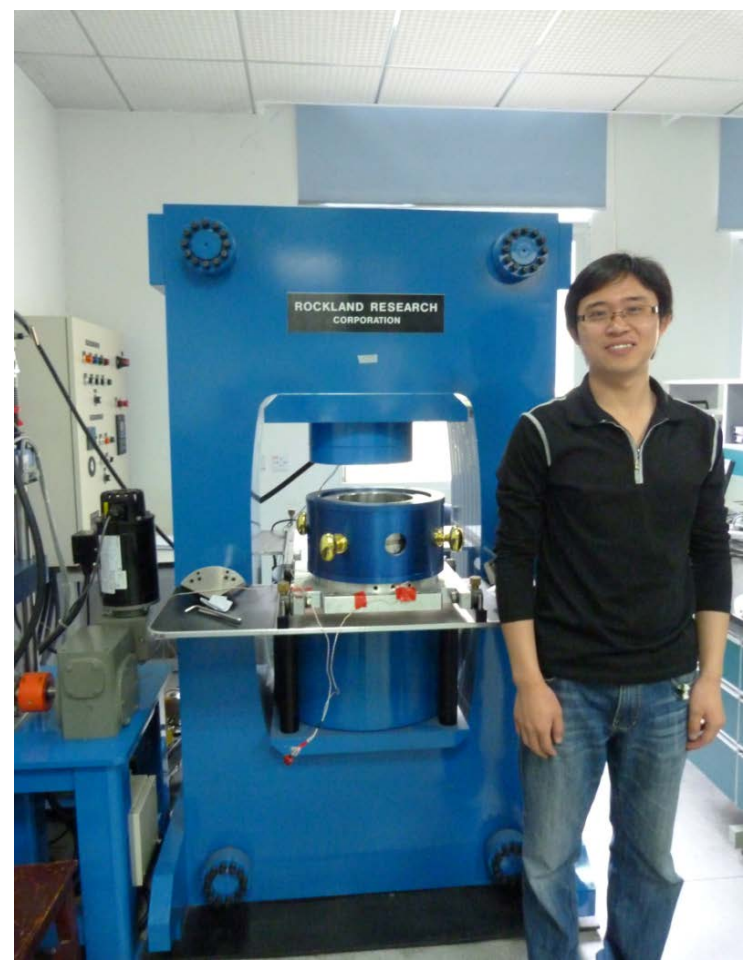

Figure 29. Yanfei Zhang with Rockland Press at CUG in Wuhan. 


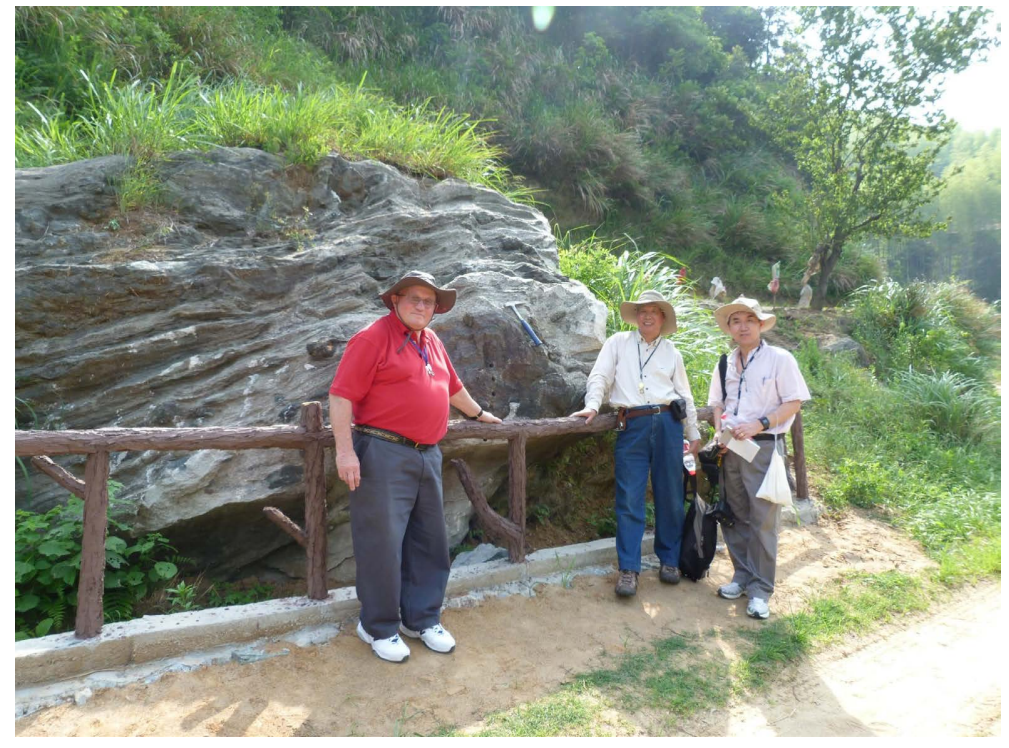

Figure 30. Bob with Zhenmin Jin and Yanbin Wang at Dabie-shan, field area for ultra-high pressure metamorphic rocks in 2011.

\section{Conclusion}

This paper summarizes the collaborations of our High-Pressure Laboratory at Stony Brook University over the past 30+ years with Chinese scientists. I have presented both the scientific achievements and the personal connections which resulted from these collaborations.

\section{Acknowledgements}

I would like to dedicate this paper to the Chinese graduate students and postdocs who have worked in our High-Pressure Laboratory at Stony Brook over the past three decades; during that period, $32 \%$ of my papers were first-authored by Chinese colleagues and 55\% of the total of 117 papers had Chinese co-authors. My collaborations with these Chinese colleagues have been supported by research grants from the NSF Geophysics Program and the NSF Science and Technology Center for High Pressure Research [CHiPR]. My visits to the mainland of China and Taiwan were supported by the host institutions: Jilin University, National Cheng Kung University, Harbin Institute of Technology and the China University of Geosciences. This report was written with support from a research grant to Baosheng $\mathrm{Li}$ and myself from the National Science Foundation (EAR-1524078). I am grateful to Yanbin Wang for suggesting that I write this paper and for providing input on the history of my collaboration with Chinese scientists, as well as comments on social developments in China over the past half century. I also acknowledge my Chinese colleagues who have provided laboratory and touristic photos for this paper.

\section{Conflicts of Interest}

The author declares no conflicts of interest regarding the publication of this paper. 


\section{References}

[1] Liebermann, R.C. (2021) Stony Brook's High-Pressure Laboratory Collaborations with French Scientists. International Journal of Geosciences, 12, 195-212. https://doi.org/10.4236/ijg.2021.123012

[2] Liebermann, R.C. (2021) Stony Brook's Collaborations with Czech Scientists. International Journal of Geosciences, 12, 487-498. https://doi.org/10.4236/ijg.2021.125026

[3] Liu, X., Wang, Y. and Liebermann, R.C. (1988) Orthorhombic-Tetragonal Phase Transition in $\mathrm{CaGeO}_{3}$ Perovskite at High Temperature. Geophysical Research Letters, 15, 1231-1234. https://doi.org/10.1029/GL015i011p01231

[4] Liu, X., Wang, Y., Liebermann, R.C., Maniar, P.D. and Navrotsky, A. (1991) Phase Transition in $\mathrm{CaGeO}_{3}$ Perovskite: Evidence from X-Ray Powder Diffraction, Thermal Expansion and Heat Capacity. Physics and Chemistry of Minerals, 18, 224-230. https://doi.org/10.1007/BF00202574

[5] Ingrin, J. and Liebermann, R.C. (1989) Deviatoric Stress in a Girdle-Anvil Type High Pressure Apparatus: Effect on the Quartz-Coesite Phase Transformation. Physics of the Earth and Planetary Interiors, 54, 378-385. https://doi.org/10.1016/0031-9201(89)90255-0

[6] Wang, Y., Liebermann, R.C. and Boland, J.N. (1988) Olivine as an in Situ Piezometer in High Pressure Apparatus. Physics and Chemistry of Minerals, 15, 493-497. https://doi.org/10.1007/BF00311130

[7] Liebermann, R.C. and Wang, Y. (1992) Charcterization of Sample Environment in a Uniaxial Split-Sphere Apparatus. In: Syono, Y. and Manghnani, M.H., Eds., High Pressure Research: Applications to Earth and Planetary Sciences, Terra Scientific Publishing Company, Washington DC, 19-31.

https://doi.org/10.1029/GM067p0019

[8] Wang, Y., Poirier J. and Liebermann, R.C. (1989) Dislocation Dissociation in Ca$\mathrm{GeO}_{3}$ Perovskite. Physics and Chemistry of Minerals, 16, 630-633. https://doi.org/10.1007/BF00223310

[9] Wang, Y., Guyot, F., Yeganeh-Haeri, A. and Liebermann, R.C. (1990) Twinning in $\mathrm{MgSiO}_{3}$ Perovskite. Science, 248, 468-471.

https://doi.org/10.1126/science.248.4954.468

[10] Wang, Y., Guyot, F. and Liebermann, R.C. (1992) Electron Microscopy of (Mg, $\mathrm{Fe}) \mathrm{SiO}_{3}$ Perovskite: Evidence of Structural Phase Transitions and Implications for the Lower Mantle. Journal of Geophysical Research, 97, 12327-12347. https://doi.org/10.1029/92JB00870

[11] Martinez, I., Wang, Y., Guyot, F., Liebermann, R.C. and Doukhan, J. (1997) Microstructures and Iron Partitioning in ( $\mathrm{Mg}, \mathrm{Fe}) \mathrm{SiO}_{3}$ Perovskite-(Mg, $\left.\mathrm{Fe}\right) \mathrm{O}$ Magnesiowustite Assemblages: An Analytical Transmission Electron Microscopy Study. Journal of Geophysical Research, 102, 5265-5280.

https://doi.org/10.1029/96JB03188

[12] Wang, Y., Martinez, I., Guyot F. and Liebermann, R.C. (1997) The Breakdown of Olivine to Perovskite and Magnesiowüstite. Science, 275, 510-513.

https://doi.org/10.1126/science.275.5299.510

[13] Cordier, P., Raterron P. and Wang, Y. (1996) TEM Investigation of Dislocation Microstructure of Experimentally Deformed Garnet. Physics of the Earth and Planetary Interiors, 97, 121-131. https://doi.org/10.1016/0031-9201(96)03154-8

[14] Wang, Y., Liu, X., Yao, G.D., Liebermann, R.C. and Dudley, M. (1991) High Tem- 
perature Transmission Electron Microscopy and X-Ray Diffraction Studies of Twinning and the Phase Transition at $145^{\circ} \mathrm{C}$ in $\mathrm{LaGaO}_{3}$. Materials Science and Engineering: $A, 132,13-21$. https://doi.org/10.1016/0921-5093(91)90356-R

[15] Yao, G.D., Dudley, M., Wang, Y., Liu, X. and Liebermann, R.C. (1991) Synchrotron $\mathrm{X}$-Ray Topography Studies of Twinning and the Phase Transition at $145^{\circ} \mathrm{C}$ in La$\mathrm{GaO}_{3}$ Single Crystals. Materials Science and Engineering: A, 132, 23-30. https://doi.org/10.1016/0921-5093(91)90357-S

[16] Wang, Y. and Liebermann, R.C. (1993) Electron Microscopy Study of Domain Structure Due to Phase Transitions in Natural Perovskite. Physics and Chemistry of Minerals, 20, 147-158. https://doi.org/10.1007/BF00200117

[17] Wang, Y., Gasparik, T. and Liebermann, R.C. (1993) Modulated Microstructures in Synthetic Majorite. American Mineralogist, 78, 1165-1173.

[18] Malavergne, V., Guyot, F., Wang Y. and Martinez, I. (1997) Partitioning of Nickel, Cobalt and Manganese between Silicate Perovskite and Periclase: A Test of Crystal Field Theory at High Pressure. Earth and Planetary Science Letters, 146, 499-509, https://doi.org/10.1016/S0012-821X(96)00234-8

[19] Liu, X. and Liebermann, R.C. (1993) X-Ray Powder Diffraction Study of $\mathrm{CaTiO}_{3}$ Perovskite at High Temperatures. Physics and Chemistry of Minerals, 20, 171-175. https://doi.org/10.1007/BF00200119

[20] Meng, Y., Weidner, D.J., Gwanmesia, G.D., Liebermann, R.C., Vaughan, M.T., Wang, Y., Leinenweber, K., Li, B., Parise, J.B., Pacalo, R.E., Yeganeh-Haeri, A. and Zhao, Y. (1993) In Situ High P-T X-Ray Diffraction Studies on Three Polymorphs $(\alpha, \beta, \gamma)$ of $\mathrm{Mg}_{2} \mathrm{SiO}_{4}$,. Journal of Geophysical Research, 98, 22199-22207. https://doi.org/10.1029/93JB02383

[21] Wang, Y., Weidner, D.J., Liebermann, R.C. and Zhao, Y. (1994) P-V-T Equation of State of $(\mathrm{Mg}, \mathrm{Fe}) \mathrm{SiO}_{3}$ Perovskite: Constraint on the Composition of the Lower Mantle. Physics of the Earth and Planetary Interiors, 83, 13-40. https://doi.org/10.1016/0031-9201(94)90109-0

[22] Liu, J., Zhang, J., Flesch, L.M., Li, B., Weidner, D.J. and Liebermann, R.C. (1999) Thermal Equation of State of Stishovite. Physics of the Earth and Planetary Interiors, 112, 257-266. https://doi.org/10.1016/S0031-9201(99)00037-0

[23] Wang, Y., Weidner, D.J., Zhang, J., Gwanmesia, G.D. and Liebermann, R.C. (1998) Thermal Equation of State of Garnets along the Pyrope-Majorite Join. Physics of the Earth and Planetary Interiors, 105, 59-71. https://doi.org/10.1016/S0031-9201(97)00072-1

[24] Guyot, F., Zhang, J., Martinez, I., Matas, J., Rickard, Y. and Javoy, M. (1997) P-V-T Measurements of Iron Silicide ( $\varepsilon$-FeSi). Implications for Silicate-Metal Interactions in the Early Earth. European Journal of Mineralogy, 9, 277-286. https://doi.org/10.1127/ejm/9/2/0277

[25] Zhang, J. and Guyot, F. (1999) Thermal Equation of State of Iron and $\mathrm{Fe}_{0.91} \mathrm{Si}_{0.09}$. Physics and Chemistry of Minerals, 26, 206-211. https://doi.org/10.1007/s002690050178

[26] Zhang J., Martinez, I., Guyot, F., Gillet, P. and Saxena, S.K. (1997) In Situ X-Ray Diffraction Study on Magnesite at High Pressure and High Temperature. Physics and Chemistry of Minerals, 24, 122-130. https://doi.org/10.1007/s002690050025

[27] Zhang J. and Guyot, F. (1999) Experimental Study of the bcc-fcc Phase Transformations in the Fe-Rich System Fe-Si at High Pressures. Physics and Chemistry of Minerals, 26, 419-424. https://doi.org/10.1007/s002690050203

[28] Guyot, F., Wang, Y., Gillet P. and Ricard, Y. (1996) Quasi-Harmonic Computations 
of Thermodynamic Parameters of Olivines at High-Pressure and High-Temperature: A Comparison with Experimental Data. Physics of the Earth and Planetary Interiors, 98, 17-29. https://doi.org/10.1016/S0031-9201(96)03174-3

[29] Bejina, F., Raterron, P., Zhang, J., Jaoul, O. and Liebermann, R.C. (1997) Activation Volume of Silicon Diffusion in San Carlos Olivine. Geophysical Research Letters, 24, 2597-2600. https://doi.org/10.1029/97GL02735

[30] Sinelnikov, Y.D., Chen, G., Neuville, D.R. and Liebermann, R.C. (1998) Ultrasonic Shear Velocities of $\mathrm{MgSiO}_{3}$-Perovskite at High Pressure and Temperature and Lower Mantle Composition. Science, 281, 677-679.

https://doi.org/10.1126/science.281.5377.677

[31] Zhang, J., Liebermann, R.C., Gasparik, T., Claude T.H. and Fei, Y. (1993) Melting and Subsolidus Relations of $\mathrm{SiO}_{2}$ at 9-14 GPa. Journal of Geophysical Research, 98, 19785-19703. https://doi.org/10.1029/93JB02218

[32] Zhang, J., Li, B., Utsumi, W. and Liebermann, R.C. (1996) In Situ X-Ray Observations of the Coesite-Stishovite Phase Transition: Reversed Phase Boundary and Kinetics. Physics and Chemistry of Minerals, 23, 1-10.

https://doi.org/10.1007/BF00202987

[33] Liu, J., Topor, L., Zhang, J., Navrotsky, A. and Liebermann, R.C. (1996) Calorimetry Study of the Coesite-Stishovite Transformation and Calculations of the Phase Boundary. Physics and Chemistry of Minerals, 23, 11-16. https://doi.org/10.1007/BF00202988

[34] Li, B., Rigden, S.M. and Liebermann, R.C. (1996) Elasticity of Stishovite at High Pressure. Physics of the Earth and Planetary Interiors, 96, 113-127. https://doi.org/10.1016/0031-9201(96)03144-5

[35] Chen, T., Gwanmesia, G.D., Wang, X., Zou, Y., Liebermann, R.C., Michaut, C. and Li, B. (2015) Anomalous Elastic Properties of Coesite at High Pressure and Implications for the Upper Mantle X-Discontinuity. Earth and Planetary Science Letters, 412, 42-51. https://doi.org/10.1016/j.epsl.2014.12.025

[36] Chen, T., Liebermann, R.C., Zou, Y., Li, Y., Qi, X. and Li, B. (2017) Tracking Silica in Earth's Upper Mantle Using New Sound Velocity Data for Coesite to $5.8 \mathrm{GPa}$ and 1073 K. Geophysical Research Letters, 44, 7757-7765.

https://doi.org/10.1002/2017GL073950

[37] Li, B., Jackson, I., Gasparik, T. and Liebermann, R.C. (1996) Elastic Wave Velocity Measurement in Multi-Anvil Apparatus to $10 \mathrm{GPa}$ Using Ultrasonic Interferometry. Physics of the Earth and Planetary Interiors, 98, 79-91. https://doi.org/10.1016/S0031-9201(96)03173-1

[38] Li, B., Chen, G., Gwanmesia. G.D. and Liebermann, R.C. (1998) Sound Velocity Measurements at Mantle Transition Zone Conditions of Pressure and Temperature Using Ultrasonic Interferometry in a Multi-Anvil Apparatus. In: Manghnani, M.H., Syono, Y. and Yagi, T., Eds., Properties of Earth and Planetary Materials at High Pressure and Temperature, American Geophysical Union, Washington DC, 41-61. https://doi.org/10.1029/GM101p0041

[39] Liebermann, R.C., and Li, B. (1998) Elasticity at High Pressures and Temperatures. In: Hemley, R.J., Ed., Ultrahigh Pressure Mineralogy, De Gruyter, Berlin, 459-492. https://doi.org/10.1515/9781501509179-017

[40] Li, B., Chen, K., Kung, J., Liebermann, R.C. and Weidner, D.J. (2002) Sound Velocity Measurement Using Transfer Function Method. Journal of Physics. Condensed Matter, 14, 11337-11342. https://doi.org/10.1088/0953-8984/14/44/478

[41] Li, B., Kung, J. and Liebermann, R.C. (2004) Modern Techniques in Measuring 
Elasticity of Earth Materials at High Pressure and High Temperature Using Ultrasonics in Conjunction with Synchrotron X-Radiation. Physics of the Earth and Planetary Interiors, 143-144, 559-574. https://doi.org/10.1016/j.pepi.2003.09.020

[42] Li, B. and Liebermann, R.C. (2007) Indoor Seismology by Probing the Earth's Interior by Using Sound Velocity Measurements at High Pressures and Temperatures. Proceedings of the National Academy of Sciences of the United States of America, 104, 9145-9150. https://doi.org/10.1073/pnas.0608609104

[43] Li, B. and Liebermann, R.C. (2014) Study of the Earth's Interior Using Measurements of Sound Velocities in Minerals by Ultrasonic Interferometry. Physics of the Earth and Planetary Interiors, 233, 135-153. https://doi.org/10.1016/j.pepi.2014.05.006

[44] Wang, X., Chen, T., Qi, X., Zou, Y., Kung, J., Yu, T., Wang, Y., Liebermann, R.C. and Li, B. (2015) Acoustic Travel Time Gauges for in Situ Determination of Pressure and Temperature in Multi-Anvil Apparatus. Journal of Applied Physics, 118, Article No. 065901. https://doi.org/10.1063/1.4928147

[45] Liebermann, R.C., Ringwood, A.E. Mayson, D.J. and Major, A. (1974) Hot-Pressing of Polycrystalline Aggregates at Very High Pressures for Ultrasonic Measurements. Proceedings of 4th International Conference on High Pressure Science and Technology, Kyoto, 25-29 November 1974, 495-502.

[46] Gwanmesia, G.D., Liebermann, R.C. and Guyot, F. (1990) Hot-Pressing and Characterization of Polycrystals of $\beta-\mathrm{Mg}_{2} \mathrm{SiO}_{4}$ for Acoustic Velocity Measurements. Geophysical Research Letters, 17, 1331-1334. https://doi.org/10.1029/GL017i009p01331

[47] Gwanmesia, G.D. and Liebermann, R.C. (1992) Polycrystals of High-Pressure Phases of Mantle Minerals: Hot-Pressing and Characterization of Physical Properties. In: Syono, Y. and Manghnani, M.H., Eds., High Pressure Research: Applications to Earth and Planetary Sciences, Terra Scientific Publishing Company, Washington DC, 117-135. https://doi.org/10.1029/GM067p0117

[48] Chen, G., Li, B. and Liebermann, R.C. (1996) Selected Elastic Moduli of Single Crystal Olivines from Ultrasonic Experiments to Mantle Pressures. Science, 272, 979-980. https://doi.org/10.1126/science.272.5264.979

[49] Chen, G., Liebermann, R.C. and Weidner, D.J. (1998) Elasticity of Single Crystal $\mathrm{MgO}$ to 8 Gigapascals and 1600 Kelvin. Science, 280, 1913-1916.

https://doi.org/10.1126/science.280.5371.1913

[50] Decremps, F., Li, B. and Liebermann, R.C. (2000) Single-Crystal Elasticity of ZnO at High Pressure, Proceedings of AIRAPT Conference. In: Manghnani, M.H., Nellis, W.J. and Nicol, M.F., Eds., High-Pressure Science and Technology, Spinger, Berlin, 810-813.

[51] Decremps, F., Zhang, J., Li, B. and Liebermann, R.C. (2001) Pressure-Induced Softening of Shear Modes in ZnO. Physical Review B, 63, Article No. 224105. https://doi.org/10.1103/PhysRevB.63.224105

[52] Sinelnikov, Y.D., Chen, G. and Liebermann, R.C. (1998) Elasticity of $\mathrm{CaTiO}_{3}-\mathrm{CaSiO}_{3}$ Perovskites. Physics and Chemistry of Minerals, 25, 515-521. https://doi.org/10.1007/s002690050143

[53] Li, B., Liebermann, R.C. and Weidner, D.J. (1998) Elastic Moduli of Wadsleyite $\left(\beta-\mathrm{Mg}_{2} \mathrm{SiO}_{4}\right)$ to 7 Gigapascals and 873 Kelvin. Science, 291, 675-677. https://doi.org/10.1126/science.281.5377.675

[54] Li, B., Liebermann, R.C. and Weidner, D.J. (2001) P-V-V $-V_{\mathrm{P}}-\mathrm{V}_{\mathrm{S}}-\mathrm{T}$ Measurements on Wadsleyite to $7 \mathrm{GPa}$ and $873 \mathrm{~K}$ : Implications for the $410-\mathrm{km}$ Seismic Discontinuity. 
Journal of Geophysical Research, 106, 30575-30591. https://doi.org/10.1029/2001JB000317

[55] Higo, Y., Inoue, T., Li, B., Irifune, T. and Liebermann, R.C. (2006) The Effect of Iron on the Elastic Properties of Ringwoodite at High Pressure. Physics of the Earth and Planetary Interiors, 159, 276-285. https://doi.org/10.1016/j.pepi.2006.08.004

[56] Chen, G., Cooke, J.A., Gwanmesia, G.D. and Liebermann, R.C. (1999) Elastic Wave Velocities of $\mathrm{Mg}_{3} \mathrm{Al}_{2} \mathrm{Si}_{3} \mathrm{O}_{12}$-Pyrope Garnet to $10 \mathrm{GPa}$. American Mineralogist, 84, 384-388. https://doi.org/10.2138/am-1999-0322

[57] Gwanmesia, G.D., Chen, G. and Liebermann, R.C. (1998) Sound Velocities in $\left(\mathrm{MgSiO}_{3}\right)$-Majorite Garnet to $8 \mathrm{GPa}$. Geophysical Research Letters, 25, 4553-4556. https://doi.org/10.1029/1998GL900189

[58] Gwanmesia, G.D., Liu, J., Chen, G., Kesson, S., Rigden, S.M. and Liebermann, R.C. (2000) Elasticity of the Pyrope $\left(\mathrm{Mg}_{3} \mathrm{Al}_{2} \mathrm{Si}_{3} \mathrm{O}_{12}\right)$-Majorite $\left(\mathrm{MgSiO}_{3}\right)$ Garnets Solid Solution. Physics and Chemistry of Minerals, 27, 445-452. https://doi.org/10.1007/s002699900054

[59] Liu, J., Chen, G., Gwanmesia, G.D. and Liebermann, R.C. (2000) Elastic Wave Velocities of Pyrope-Majorite Garnets $\left(\mathrm{Py}_{62} \mathrm{Mj}_{38}\right.$ and $\left.\mathrm{Py}_{50} \mathrm{Mj}_{50}\right)$ to $9 \mathrm{GPa}$. Physics of the Earth and Planetary Interiors, 120, 153-163. https://doi.org/10.1016/S0031-9201(00)00152-7

[60] Gwanmesia, G.D., Zhang, J., Darling, K., Kung, J., Li, B., Wang, L., Neuville, D. and Liebermann, R.C. (2006) Elasticity of Polycrystalline Pyrope $\left(\mathrm{Mg}_{3} \mathrm{Al}_{2} \mathrm{Si}_{3} \mathrm{O}_{12}\right)$ to 9 $\mathrm{GPa}$ and $1000^{\circ} \mathrm{C}$. Physics of the Earth and Planetary Interiors, 155, 179-190. https://doi.org/10.1016/j.pepi.2005.10.008

[61] Gwanmesia, G.D., Wang, L., Triplett, R. and Liebermann, R.C. (2009) Pressure and Temperature Dependence of the Elasticity of Pyrope-Majorite [Py60Mj40 and Py50Mj50] Garnets Solid Solution Measured by Ultrasonic Interferometry Technique. Physics of the Earth and Planetary Interiors, 174, 105-112. https://doi.org/10.1016/j.pepi.2008.07.029

[62] Decremps, F., Zhang, J. and Liebermann, R.C. (2000) New Phase Boundary and High Pressure Thermoelasticity of ZnO. Europhysics Letters, 51, 268-274. https://doi.org/10.1209/epl/i2000-00347-0

[63] Kung, J., Li, B., Weidner, D.J., Zhang, J. and Liebermann, R.C. (2002) Elasticity of $\left(\mathrm{Mg}_{0.83}, \mathrm{Fe}_{0.17}\right) \mathrm{O}$ Ferropericlase at High Pressure: Ultrasonic Measurements in Conjunction with X-Radiation Techniques. Earth and Planetary Science Letters, 203, 557-566. https://doi.org/10.1016/S0012-821X(02)00838-5

[64] Li, B. and Neuville, D.R. (2010) Elasticity of Diopside to $8 \mathrm{GPa}$ and $1073 \mathrm{~K}$ and Implications for the Upper mantle. Physics of the Earth and Planetary Interiors, 183, 398-403. https://doi.org/10.1016/j.pepi.2010.08.009

[65] Kung, J., Li, B., Uchida, T., Wang, Y., Neuville, D. and Liebermann, R.C. (2004) In Situ Measurements of Sound Velocities and Densities across the Orthopyroxene $\rightarrow$ High-Pressure Clinopyroxene Transition in $\mathrm{MgSiO}_{3}$ at High Pressure. Physics of the Earth and Planetary Interiors, 147, 27-44. https://doi.org/10.1016/j.pepi.2004.05.008

[66] Kung, J., Li, B. and Liebermann R.C. (2006) Ultrasonic Observations of Elasticity Changes across Phase Transformations in $\mathrm{MgSiO}_{3}$ Pyroxenes. Journal of Physics and Chemistry of Solids, 67, 2051-2055. https://doi.org/10.1016/j.jpcs.2006.05.028

[67] Wang, S., Chen, T., Cai, N., Qi, X., Fiege, A., Liebermann, R.C. and Li, B. (2019) Pressure-Induced Velocity Softening in Natural Orthopyroxene at Mantle Temper- 
ature. American Mineralogist, 104, 1173-1179. https://doi.org/10.2138/am-2019-6935

[68] Wang, X., Chen, T., Zou, Y., Liebermann, R.C. and Li, B. (2015) Elastic Wave Velocities of Peridotite KLB-1 at Mantle Pressures and Implications for Mantle Velocity Modeling. Geophysical Research Letters, 42, 3289-3297. https://doi.org/10.1002/2015GL063436

[69] Zou, Y., Zang, W., Chen, T., Li, X., Wang, C., Qi, X., Wang, S., Yu, T., Liu, B., Wang, Y., Liebermann, R.C., Zhao, Y. and Li, B. (2018) Thermally-Induced Anomaly in the Shear Behavior of Magnetite at High Pressure. Physical Review Applied, 10, Article No. 024009. https://doi.org/10.1103/PhysRevApplied.10.024009

[70] Chen, T., Gwanmesia, G.D., Ehm, L., Le Losq, C., Neuville, D.R., Phillips, B.L., Li, B. and Liebermann, R.C. (2019) Synthesis and Characterization of Polycrystalline in $\mathrm{KAlSi}_{3} \mathrm{O}_{8}$-Hollandite [Liebermannite]: Sound Velocities vs. Pressure to $13 \mathrm{GPa}$ at Room Temperature. Comptes Rendus Geosciences, 151, 113-120. https://doi.org/10.1016/j.crte.2018.09.009

[71] Qi, X., Cai, N., Wang, S. and Li, B. (2018) Experimental and Theoretical Studies on the Elasticity of Tungsten to $13 \mathrm{GPa}$. Journal of Applied Physics, 124, Article No. 075303. https://doi.org/10.1063/1.5036531

[72] Cai, N., Qi, X., Chen, T., Wang, S., Yu, T., Wang, Y., et al. (2021) Enhanced Visibility of Subduction Slabs by the Formation of Dense Hydrous Phase A. Geophysical Research Letters, 48, e2021GL095487. https://doi.org/10.1029/2021GL095487

[73] Wang, S., Cai, N., Qi, X., Chen, S. and Li, B. (2021) Sound Velocities of Iron-Nickel $\left(\mathrm{Fe}_{90} \mathrm{Ni}_{10}\right)$ Alloy up to $8 \mathrm{GPa}$ and $773 \mathrm{~K}$ : The Effect of Nickel on the Elastic Properties of bcc-Iron at High P-T. American Mineralogist. https://doi.org/10.2138/am-2021-7716.

[74] Chen, S., Cai, N., Wang, S., Qi, X. and Li, B. (2021) Implications of Sound Velocities of Natural Topaz on the Seismic L-Discontinuity. Geophysical Research Letters. (Submitted and in Review)

[75] Zou, Y, Qi, X., Wang, X., Chen, T., Li, X., Welch, D. and Li, B. (2014) High-Pressure Behavior and Thermoelastic Properties of Niobium Studied by in Situ X-Ray Diffraction. Journal of Applied Physics, 116, Article No. 013516. https://doi.org/10.1063/1.4887436

[76] Qi, X., Wang, S., Chen, S., Cai, N. and Li, B. (2021) Anomalous Elastic Behavior of Tantalum at High Pressures: Experimental and Theoretical Studies. International Journal of Refractory Metals and Hard Materials, 101, Article No.105691.

[77] Cai, N., Chen, T., Qi, X.T., Inoue, T. and Li, B.S. (2019) Sound Velocities of the 23 $\AA$ Phase at High Pressure and Implications for Seismic Velocities in Subducted Slabs. Physics of the Earth and Planetary Interiors, 288, 1-8. https://doi.org/10.1016/j.pepi.2019.01.006

[78] Cai, N., Chen, T., Qi, X.T. and Li, B.S. (2018) Elastic Anomalies Across Phase Transitions of Praseodymium to $12 \mathrm{GPa}$. Journal of Applied Physics, 124, 185901. https://doi.org/10.1063/1.5046311 


\section{Bob's Graduate Students from China at Stony Brook}

Ren Lu (1990)-M.S.

Subject: Study of kinetic rates of transformation between garnet and perovskite phases of $\mathrm{CaGeO}_{3}$.

Yanbin Wang (1991) - Ph.D

Subject: Electron microscopy and X-ray diffraction studies on structural phase transitions in $\mathrm{MgSiO}_{3}$ perovskite.

Baosheng Li (1993)-M.S.

Subject: Polycrystalline Stishovite: Hot-pressing and elastic properties.

Baosheng Li (1996) - Ph.D.

Subject: Ultrasonic Measurements of the Elastic Wave Velocities of Olivine and Beta Polymorphs of $\mathrm{Mg}_{2} \mathrm{SiO}_{4}$ at Mantle Transition Zone P and T and Geophysical Implications.

Jun Liu (1997)-M.S.

Subject: Calorimetry study of the coesite-stishovite transformation and calculation of the phase boundary.

Jun Liu (2001) - Ph.D.

Subject: Elasticity of Pyrope-Majorite Garnets at High Pressures and Temperatures and Implications for Geophysics.

\section{Baosheng's Students for Whom Bob Served as Co-Advisor}

Xuebing Wang (2016) - PhD

Subject: Mantle composition and temperature of western North America revealed from in-situ velocity measurements of KLB-1.

Ting Chen (2017) - PhD

Elasticity of coesite and stishovite: implications for the Earth's mantle.

Xingtong Qi (2019)—PhD

Elastic Propertes of Selected Transition Metals at Extreme Conditions: High Pressure and Temperature.

Siheng Wang-current PhD student.

Sibo Chen-current PhD student. 